OPEN ACCESS

Edited by:

Fred Asiegbu,

University of Helsinki, Finland

Reviewed by:

Thomas Nussbaumer, Helmholtz-Gemeinschaft Deutscher Forschungszentren (HZ), Germany William Edward Dyer, Montana State University, United States

*Correspondence: Ricky W. Lewis ricky.w.lewis@gmail.com Tarah S. Sullivan

t.sullivan@wsu.edu

Specialty section: This article was submitted to Fungi and Their Interactions,

a section of the journal

Frontiers in Microbiology

Received: 07 October 2019 Accepted: 10 January 2020

Published: 04 February 2020

Citation:

Lewis RW, Okubara PA, Fuerst EP, He R, Gang D and Sullivan TS (2020)

Chronic Sublethal Aluminum Exposure and Avena fatua Caryopsis Colonization Influence Gene Expression of Fusarium avenaceum F.a. 1. Front. Microbiol. 11:51. doi: 10.3389/fmicb.2020.00051

\section{Chronic Sublethal Aluminum Exposure and Avena fatua Caryopsis Colonization Influence Gene Expression of Fusarium avenaceum F.a.1}

Ricky W. Lewis ${ }^{1 *}$, Patricia A. Okubara ${ }^{2}$, E. Patrick Fuerst ${ }^{1}$, Ruifeng $\mathrm{He}^{3}$, David Gang ${ }^{3}$ and Tarah S. Sullivan ${ }^{1 *}$

${ }^{1}$ Department of Crop and Soil Sciences, Washington State University, Pullman, WA, United States, ${ }^{2}$ Wheat Health, Genetics, and Quality, USDA-ARS, Pullman, WA, United States, ${ }^{3}$ Institute of Biological Chemistry, Washington State University, Pullman, WA, United States

Fusarium avenaceum F.a.1 is a novel strain of a fungal plant pathogen capable of preferentially decaying wild oat (Avena fatua) caryopses compared with those of wheat (Triticum aestivum). Understanding the molecular mechanisms governing weed seed-pathogen interactions is crucial to developing novel weed seed suppression technologies. Additionally, wild oat often competes with wheat in regions undergoing soil acidification, which leads to increases in soluble concentrations of many metals, including aluminum (Al). There is a dearth of information regarding the gene expression responses of Fusarium species to Al toxicity, or how metal toxicity might influence caryopsis colonization. To address this, a transcriptomic approach was used to investigate molecular responses of F.a.1 during wild oat caryopsis colonization in the presence and absence of chronic, sublethal concentrations of Al (400 $\mu \mathrm{M})$. Caryopsis colonization was associated with induction of genes related to virulence, development, iron metabolism, oxidoreduction, stress, and detoxification, along with repression of genes associated with development, transport, cell-wall turnover, and virulence. Caryopsis colonization during $\mathrm{Al}$ exposure resulted in the induction of genes associated with virulence, detoxification, stress, iron metabolism, oxidoreduction, and cell wall turnover, along with repression of genes associated with cell wall metabolism, virulence, development, detoxification, stress, and transcriptional regulation. Aluminum exposure in the absence of caryopses was associated with induction of genes involved in siderophore biosynthesis, secretion, uptake, and utilization, along with several other iron metabolism-related and organic acid metabolism-related genes. The siderophorerelated responses associated with Al toxicity occurred concurrently with differential regulation of genes indicating disruption of iron homeostasis. These findings suggest Al toxicity is attenuated by siderophore metabolism in F.a.1. In summary, both caryopsis colonization and Al toxicity uniquely influence transcriptomic responses of F.a.1.

Keywords: wild oat, Fusarium, weed seed decay, fungal siderophore, soil acidification, sublethal aluminum toxicity, plant pathogens, soil microbiology 


\section{INTRODUCTION}

Agronomic weeds are a global issue that result in billions of dollars in annual economic losses (Pimentel et al., 2001). Weed seeds exist in high densities in soils, and may persist for many years due to long-term dormancy and decay resistance [as reviewed by Pollard (2018)]. Promoting microbial-driven seed decay is a potential ecological approach to long-term weed management by depleting the weed seedbank. In temperate regions of the world, including wheat-growing regions, wild oat (Avena fatua) is considered one of the ten worst weeds (Beckie et al., 2012). A major factor contributing to the persistence of A. fatua is that seeds can remain dormant in the soil for many years, thus generating a large soil seedbank that can readily develop herbicide resistance (Beckie et al., 2012).

Work by de Luna et al. (2011) resulted in hundreds of soil fungi isolates from dormant wild oat seeds, and it was found that Fusarium avenaceum isolate F.a.1 elicited the most rapid and pronounced decay of wild oat seeds. Successive studies in vitro showed F.a.1 is capable of preferentially decaying A. fatua compared with wheat caryopses (seeds without hulls), and that the fungus induces activity of several defense enzymes, including polyphenol oxidase, chitinase, and peroxidase, in both whole caryopses and caryopsis leachates (the soluble enzyme fraction) (Anderson et al., 2010; Fuerst et al., 2011, 2014, 2018). The latest work showed that incubation of wheat and wild oat seeds on a F.a.1 fungal mat resulted in a rapid increase in decay rating of wild oat, while wheat seeds germinated (Fuerst et al., 2018). F.a.1 exposure also resulted in increased polyphenol oxidase in wild oat and wheat caryopses, though the increase was 3.4 times that of the pathogen-free control in wild oat, and 1.8 times in wheat (Fuerst et al., 2018).

In addition to weed pressure, wheat production is often complicated by soil acidification, primarily due to the addition of ammoniacal fertilizers, which can have a strong influence on metal bioavailability, soil chemistry, and microbial communities (Schroder et al., 2011; Lewis et al., 2018). Soil acidification is a global issue currently affecting a large percentage of the world's arable land (von Uexküll and Mutert, 1995), and the toxicity of soluble $\mathrm{Al}$ in acidic soils is thought to be a major factor in limiting plant growth (Foy, 1984). It has been hypothesized that many microbes can produce metal-chelating compounds, such as siderophores and organic acids, that may play a role in metal availability in the soil (Jones et al., 2003; Glick, 2010). Still, it is unclear how fungal plant pathogens respond to $\mathrm{Al}$ toxicity at the molecular level. In addition to revealing fundamental molecular mechanisms involved in $\mathrm{Al}$ toxicity, understanding how fungal plant pathogens might respond to this important aspect of soil acidification might assist in developing methods of weed seedbank control as soils acidify.

Work examining the $F$. avenaceum genome has shown it is enriched in transcription factors, redox-related proteins, and signal transduction proteins (Lysøe et al., 2014). Additionally, the $F$. avenaceum transcriptome was found to be enriched in gene ontology (GO) categories related to membrane activity, ATP/GTP binding, and calcium ion binding
(Lysøe et al., 2014). One objective of the current work is to examine the transcriptomic changes associated with fungal colonization of A. fatua caryopses. Doing so should provide key insights into the molecular mechanisms governing A. fatua caryopsis colonization. Another objective is to examine the influence of Al toxicity on fungal gene expression in the absence and presence of $A$. fatua caryopses. Addressing this last objective would provide information regarding how $F$. avenaceum responds to aluminum toxicity while also examining how $\mathrm{Al}$ influences the fungal transcriptome during colonization of caryopses. The ultimate objective of the work is to elucidate fungal genes which may be of use in future endeavors to develop weed seed suppression technologies through promotion of weed seedbank destruction.

\section{MATERIALS AND METHODS}

\section{Fungal Culturing}

Filter disk segments containing mycelium from $F$. avenaceum F.a.1 were transferred to potato dextrose agar (PDA: 24 g potato dextrose $\mathrm{L}^{-1}+15 \mathrm{~g}$ agar $\left.\mathrm{L}^{-1}\right)$ plates $(25 \mathrm{~mL})$. After 13 days of growth, $6 \mathrm{~mm}$ plugs were taken with a sterile core sampler and placed to $25 \mathrm{~mL}$ PDA plates that had been amended $72 \mathrm{~h}$ earlier, with $1 \mathrm{~mL}$ of double-deionized (DDI) sterile $\mathrm{H}_{2} \mathrm{O}\left(\mathrm{PDA}-\mathrm{H}_{2} \mathrm{O}\right)$, or $1 \mathrm{~mL}$ of $10 \mathrm{mM} \mathrm{AlCl}_{3}$ (PDA-Al). All plates were incubated in dark conditions at $22^{\circ} \mathrm{C}$.

\section{Plant-Fungal Interaction and Tissue Sampling}

Fungal culture diameter was measured at 2, 4, 7, and 11 days post inoculation (DPI); note that fungal colony diameter data are only shown for samples used in the RNA-Seq studies, so there are 12 replicates per treatment (water and $\mathrm{Al}$ ) (Figure 1). After 8 days of growth on PDA- $\mathrm{H}_{2} \mathrm{O}$ or PDA-Al, 30 dry wild oat (Avena fatua) caryopses were placed along the growing edge of the fungal mycelial mat on nine plates of each treatment. Caryopses were also placed on $25 \mathrm{~mL}$ water agar plates $\left(15 \mathrm{~g}\right.$ agar $\left.\mathrm{L}^{-1}\right)$ with one $\mathrm{mL}$ of DDI $\mathrm{H}_{2} \mathrm{O}\left(\right.$ Agar- $\left.\mathrm{H}_{2} \mathrm{O}\right)$, or one $\mathrm{mL} 10 \mathrm{mM} \mathrm{AlCl}_{3}$ (Agar-Al), without the fungus; these plates were previously prepared and treated along with the PDA plates described above. After addition of caryopses, the plates were incubated in dark conditions at $15^{\circ} \mathrm{C}$ for 3 days $(72 \mathrm{~h})$. The decreased temperature was used to discourage germination of the caryopses.

After $72 \mathrm{~h}$, caryopses were gently removed from the fungal mat using sterile forceps, large fungal fragments were carefully removed, and then the caryopses were placed in sterile $2 \mathrm{~mL}$ tubes. Six replicates per treatment of the caryopses samples were set aside for a separate study, and three replicates of each treatment were used for polyphenol oxidase (PPO) activity assays. The fungal tissue was gently scraped from the PDA plates using a sterile spatula, and placed in sterile $2 \mathrm{~mL}$ tubes. All tubes were massed before and after loading samples and were immediately placed in liquid $\mathrm{N}_{2}$ after massing. Samples were then maintained at $-80^{\circ} \mathrm{C}$ before RNA extraction. Throughout the manuscript the treatments are indicated as follows, FOW $=$ fungus only + water, $\mathrm{FW}=$ fungus + caryopsis 


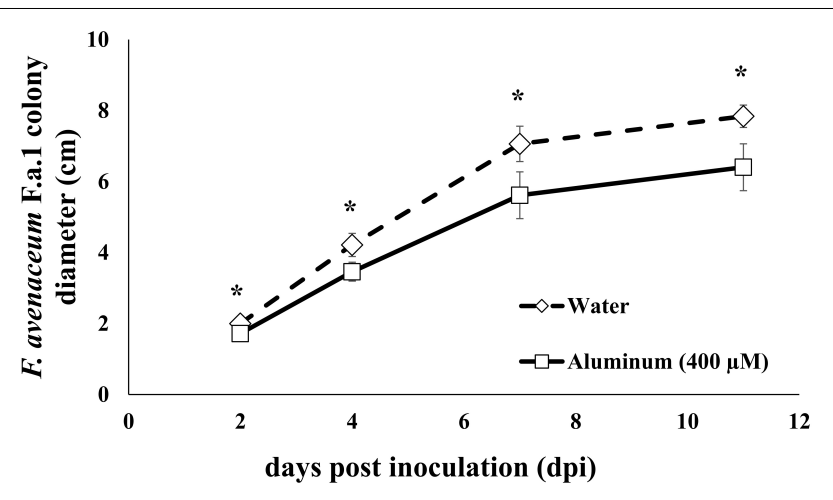

FIGURE 1 | Fungal colony diameter of Fusarium avenaceum F.a.1 in cm. Days post inoculation (dpi) is days after transferring a $6 \mathrm{~mm}$ plug of colonized potato dextrose agar (PDA; $25 \mathrm{~mL}$ ) to the center of fresh PDA ( $25 \mathrm{~mL}$ ) amended with either $1 \mathrm{~mL}$ of water (diamond; dotted line) or $1 \mathrm{~mL}$ of $10 \mathrm{mM} \mathrm{AICl}_{3}$ (squares; solid lines; $400 \mu \mathrm{M}$ is final aluminum concentration). Data represent samples used in transcriptomic studies. Because caryopses were not added until day eight, colony diameter analyses have 12 replicates for each treatment (water or Al). Asterisks indicate statistical significance at alpha $=0.05$.

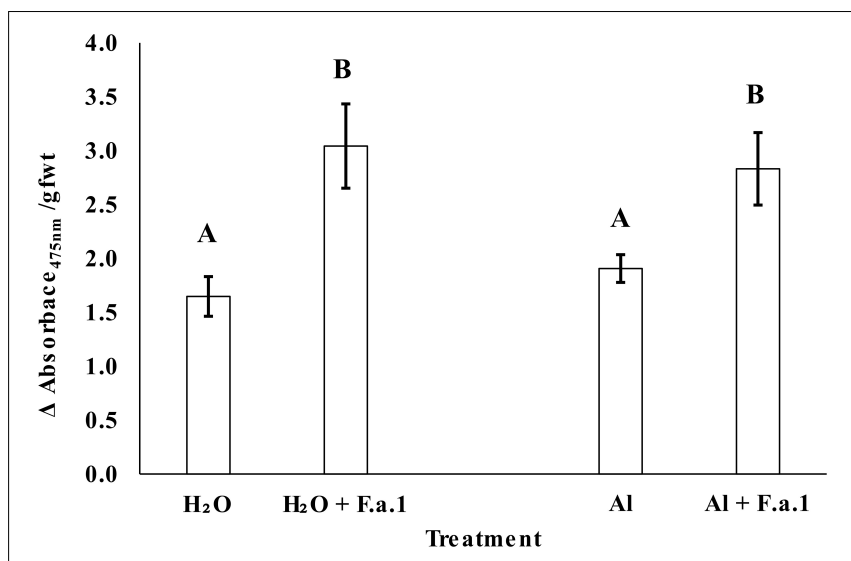

FIGURE 2 | Polyphenol oxidase (PPO) activity in whole caryopses presented as average change $(\Delta)$ in absorbance at $475 \mathrm{~nm}$ divided by caryopsis grams fresh weight (gfwt). Bars are standard deviation and letters represent significance evaluated at alpha $=0.05$. Caryopses in the absence of Fusarium avenaceum F.a.1 (F.a.1) were sampled from $25 \mathrm{~mL}$ water agar plates amended with $1 \mathrm{~mL}$ of water $\left(\mathrm{H}_{2} \mathrm{O}\right)$ or $10 \mathrm{mM} \mathrm{AlCl}_{3}(\mathrm{Al})$. Caryopses in the presence of F.a. 1 were sampled from $25 \mathrm{~mL}$ PDA plates with the same amendments.

+ water, $\mathrm{FOA}=$ fungus only $+\mathrm{Al}$, and $\mathrm{FA}=$ fungus + caryopsis $+\mathrm{Al}$.

\section{PPO Activity in Caryopses}

Whole caryopsis PPO activity was assayed spectrophotometrically as previously described (Fuerst et al., 2018). Using forceps, caryopses were gently removed from Agar- $\mathrm{H}_{2} \mathrm{O}$ and Agar-Al plates, and from the fungal mycelial bed from the fungus grown on PDA- $\mathrm{H}_{2} \mathrm{O}$ and PDA-Al (three replicates each). Three plates per treatment were dedicated to the PPO assays, and three replicates composed of five caryopses each were gathered from each plate and transferred to a tared 2 - $\mathrm{mL}$ microcentrifuge tube, and samples were re-weighed.
Samples were incubated in $1.25 \mathrm{~mL}$ substrate solution consisting of $10 \mathrm{mM}$ L-DOPA (L-3,4-dihydroxyphenylalanine) at $\mathrm{pH}$ 6.5. Samples were incubated at room temperature on an endover-end shaker for $25 \mathrm{~min}$ and the reaction was terminated with $1 \mathrm{mM}$ tropolone (2-hydroxy-2,4,6-cycloheptatrien1 -one). Samples were centrifuged to remove particulate contaminants and $300 \mu \mathrm{L}$ of supernatant was transferred to a microtiter plate in duplicate. Absorbance at $475 \mathrm{~nm}$ was determined with a spectrophotometer (BioTek Epoch; BioTek Instruments, Inc., Winooski, VT, United States). Results are reported as change in optical density per gram fresh weight of caryopses $\left(\mathrm{gfwt}^{-1}\right)$.

\section{RNA Extraction, Sequencing, and Analysis}

Six replicates from each treatment were used for fungal transcriptome studies. Samples ranging from 56 to $271 \mathrm{mg}$ were collected and put into $2 \mathrm{~mL}$ safe-lock tubes (Eppendorf) at $-80^{\circ} \mathrm{C}$. Samples were prepared by precooling TissueLyser adapter sets in liquid nitrogen and adding two sterilized $2.88 \mathrm{~mm}$ stainless steel beads in each sample tube, then sample homogenates were generated using a TissueLyser II (Qiagen) with a frequency setting of 30 for $40 \mathrm{~s}$. About $50 \mathrm{mg}$ sample powder for each sample was collected in $0.5 \mathrm{~mL}$ Trizol (Invitrogen, Carlsbad, CA, United States). For RNA extraction, $0.3 \mathrm{~mL}$ chloroform was added to $0.5 \mathrm{~mL}$ Trizol homogenates, followed by vigorous sample shaking for $2 \mathrm{~min}$. Samples were transferred to $1.5 \mathrm{~mL}$ tubes, and then allowed to sit for $3 \mathrm{~min}$ at room temperature, followed by centrifugation at $12,000 \times \mathrm{g}$ for $15 \mathrm{~min}$ at $4^{\circ} \mathrm{C}$ to assist with separation of organic and aqueous phases. The aqueous phase $(\sim 250 \mu \mathrm{L})$ was then transferred to a new sterile RNase-free tube and an equal volume of $100 \% \mathrm{EtOH}$ was added, with mixing as needed. Samples were further purified using the RNeasy Mini Kit (Qiagen, Valencia, CA, United States) according to the manufacturer's protocol. The quality and quantity of each RNA sample was assessed using a NanoDrop 2000 Spectrophotometer (Thermo Scientific, Wilmington, DE, United States), and an Agilent 2100 Bioanalyzer (Agilent, Santa Clara, CA, United States).

Libraries were prepared using the TruSeq RNA Library Prep Kit (Illumina, San Diego, CA, United States). Nextgeneration sequencing was performed by Novogene Inc. using an Illumina NovaSeq 6000 (paired-end, $2 \times 150$ bp, 20 million reads per sample). Reads were filtered by discarding those with adaptor contamination, uncertain nucleotides $>10 \%$, and/or base quality $<20$ for more than $50 \%$ of the read. The Fusarium avenaceum genome was used as a reference and mapping was performed using TopHat (v2.0.12) with mismatch $=2$ (Trapnell et al., 2009). HTSeq (v0.6.1) was used for quantification using the "union" mode (Anders et al., 2015). DESeq (v1.120.1) was used for assessing differentially expressed genes (DEGs) with significance assessed using an adjusted $p$-value of 0.05 (Anders and Huber, 2010). Reported differentially expressed genes were further trimmed to include only those with $\mid \mathrm{LOG}_{2}$ (Fold Change) $\mid \geq 2$ (which is a 4 -fold 
change), and only genes with at least 14 average reads in one of the treatments being compared were discussed. Genes were annotated using the Swiss-Prot (UniProt Consortium, 2018) and GenBank (Coordinators, 2016) databases (Supplementary Tables S1-S3). Kyoto Encyclopedia of Genes and Genomes (KEGG) (Kanehisa and Goto, 2000) enrichment analysis was performed using Fusarium graminearum (Walkowiak et al., 2016) as a reference and KOBAS (v3.0) with significance evaluated at an adjusted $p$-value of 0.05 . GO enrichment was assessed using HMMER (v3.1b1) and significance assessed using an adjusted $p$-value of 0.05 (Eddy, 2011). All adjusted $p$-values were obtained using the FDR method. Information regarding RNA quality and RNA-Seq quality control can be found in supplemental information (Supplementary Tables S4S6). Counts of genes that were uniquely expressed and exhibited statistically significant expression (DEGs) were summarized in
Supplementary Table S7; these data were further filtered to only include gene ontology terms with $\geq 5$ DEGs. Raw sequencing data are available via the Sequence Read Archive (SRA; SRA accession: PRJNA595343).

\section{RESULTS}

\section{Aluminum Influences Colony Formation but Not PPO Activity in Caryopses}

Chronic sublethal exposure of F.a.1 to $400 \mu \mathrm{M}$ Al resulted in inhibited fungal colony formation that persisted across the study, starting at 2 days post inoculation (dpi) until tissue harvesting at $11 \mathrm{dpi}$ (Figure 1). Fungal colonies on control plates containing water ultimately reached an average diameter of $7.8 \mathrm{~cm}$, while those exposed to $\mathrm{Al}$ reached an

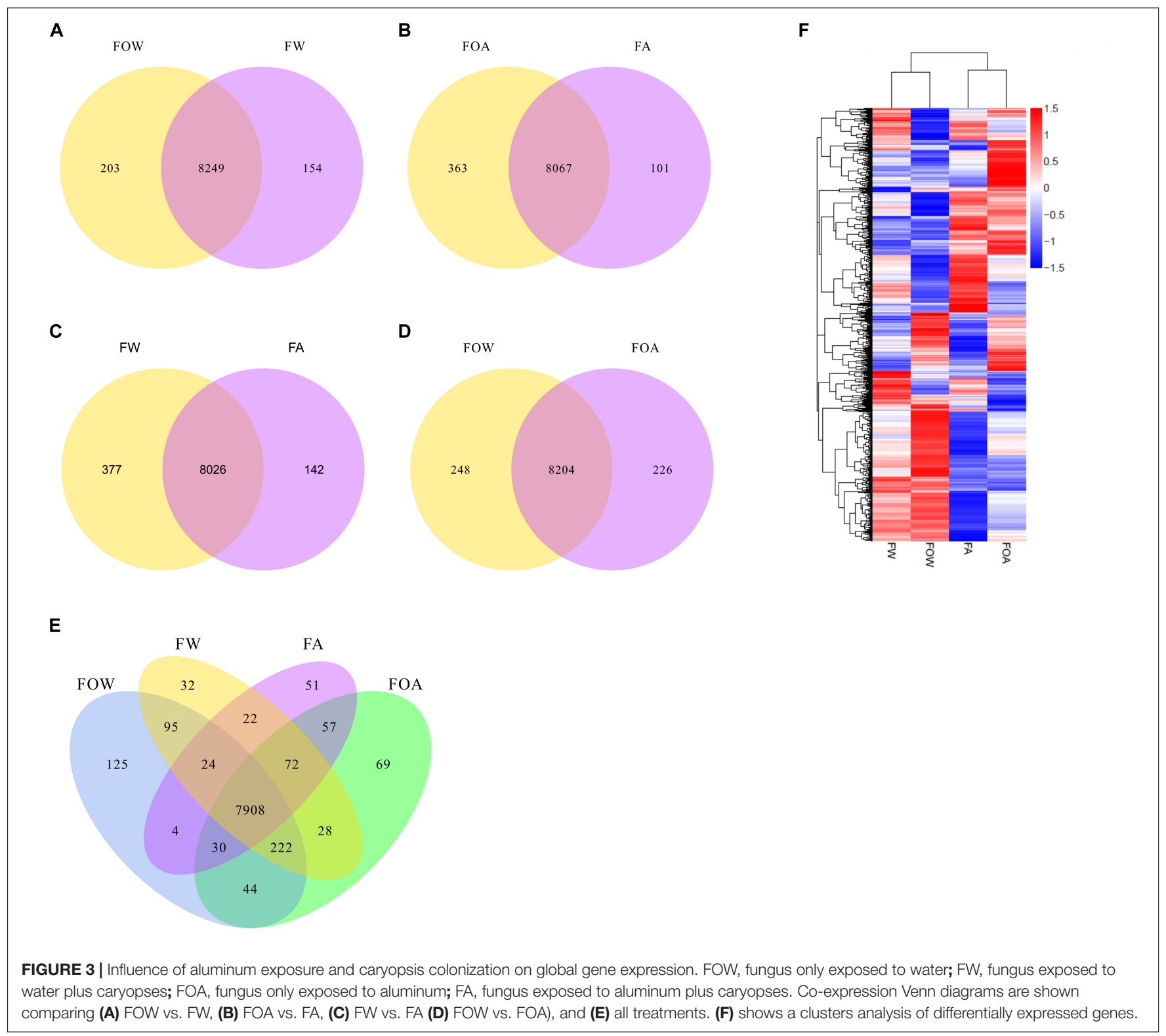


TABLE 1 | Caryopsis-induced differentially expressed genes in F. avenaceum F.a.1. in the absence of aluminum (FW vs. FOW).

\begin{tabular}{|c|c|c|c|}
\hline Transcript ID & $\begin{array}{l}\text { Gene name/ } \\
\text { function }\end{array}$ & $\begin{array}{l}\quad \log _{2} \\
\text { (Fold change) }\end{array}$ & $\begin{array}{l}\text { Subcellular } \\
\text { localization }\end{array}$ \\
\hline & Virulence & & \\
\hline KIL85362.1 & Ga4 desaturase & 3.1 & NF \\
\hline KIL90538.1 & Ent-kaurene oxidase & 3.1 & integral component of membrane [GO:0016021] \\
\hline KIL91977.1 & Thaumatin-like protein & 2.8 & extracellular region [GO:0005576] \\
\hline KIL89103.1 & Catalase-1 & 2.7 & $\begin{array}{l}\text { ascospore wall [GO:0005619]; cytosol [GO:0005829]; extracellular } \\
\text { region [GO:0005576] }\end{array}$ \\
\hline KIL83809.1 & Aldehyde dehydrogenase & 2.5 & cytoplasm [GO:0005737] \\
\hline KIL87894.1 & Oxalate decarboxylase OxdD & 2.3 & cytoplasm [GO:0005737] \\
\hline KIL92157.1 & Acetyl-CoA hydrolase & 2.1 & mitochondrion [GO:0005739] \\
\hline \multirow[t]{2}{*}{ KIL87701.1 } & Related to 2'-hydroxyisoflavone reductase & 2.1 & NF \\
\hline & Detoxification/Stress & & \\
\hline KIL92628.1 & Uncharacterized MFS-type transporter C409.08 & 7.1 & $\begin{array}{l}\text { fungal-type vacuole membrane [GO:0000329]; integral component } \\
\text { of plasma membrane [GO:0005887]; plasma membrane } \\
\text { [GO:0005886] }\end{array}$ \\
\hline KIL88411.1 & Aflatoxin B1 aldehyde reductase member 4 & 6.4 & cytosol [GO:0005829]; extracellular exosome [GO:0070062] \\
\hline KIL94023.1 & Peroxisomal catalase & 5.2 & peroxisome [GO:0005777] \\
\hline KIL85820.1 & Uncharacterized transporter C794.04c & 4.3 & $\begin{array}{l}\text { fungal-type vacuole membrane [GO:0000329]; integral component } \\
\text { of plasma membrane [GO:0005887]; plasma membrane } \\
\text { [GO:0005886] }\end{array}$ \\
\hline KIL87621.1 & Nitrosoguanidine resistance protein & 3.9 & integral component of membrane [GO:0016021] \\
\hline KIL88862.1 & Uncharacterized transporter C36.03c & 3.9 & $\begin{array}{l}\text { endoplasmic reticulum [GO:0005783]; fungal-type vacuole } \\
\text { [GO:0000324]; fungal-type vacuole membrane [GO:0000329]; } \\
\text { integral component of plasma membrane [GO:0005887]; plasma } \\
\text { membrane [GO:0005886] }\end{array}$ \\
\hline KIL86787.1 & Aldehyde dehydrogenase & 3.9 & extracellular region [GO:0005576] \\
\hline KIL88163.1 & Cytochrome P450 4F6 & 3.6 & endoplasmic reticulum membrane [G0:0005789] \\
\hline KIL89486.1 & Putative cryptochrome DASH & 3.4 & NF \\
\hline KIL90370.1 & 11-oxo-beta-amyrin 30-oxidase & 3.3 & integral component of membrane [GO:0016021] \\
\hline KIL86788.1 & Aldehyde dehydrogenase & 2.9 & $\mathrm{NF}$ \\
\hline KIL89668.1 & Glutathione s-transferase & 2.8 & NF \\
\hline KIL85730.1 & Zinc finger protein MSN4 & 2.7 & cytosol [GO:0005829]; nucleus [GO:0005634] \\
\hline KIL87533.1 & Dienelactone hydrolase & 2.6 & $\mathrm{NF}$ \\
\hline KIL86609.1 & Cytochrome P450 4F5 & 2.6 & endoplasmic reticulum membrane [GO:0005789] \\
\hline KIL86151.1 & Brefeldin A resistance protein & 2.6 & $\begin{array}{l}\text { integral component of membrane [GO:0016021]; plasma } \\
\text { membrane [GO:0005886] }\end{array}$ \\
\hline KIL93695.1 & Isotrichodermin C-15 hydroxylase & 2.6 & integral component of membrane [GO:0016021] \\
\hline KIL95553.1 & Glutathione-independent glyoxalase HSP31 & 2.6 & cytoplasmic stress granule [GO:0010494]; P-body [GO:0000932] \\
\hline KIL90371.1 & Cholesterol 7-alpha-monooxygenase & 2.4 & $\begin{array}{l}\text { cell [GO:0005623]; endoplasmic reticulum membrane } \\
\text { [GO:0005789]; integral component of membrane [GO:0016021]; } \\
\text { intracellular membrane-bounded organelle [GO:0043231] }\end{array}$ \\
\hline \multirow[t]{2}{*}{ KIL84900.1 } & Activator of stress genes 1 & 2.3 & nucleus [GO:0005634] \\
\hline & Oxidoreduction & & \\
\hline KIL87958.1 & $\begin{array}{l}\text { Zinc-type alcohol dehydrogenase-like protein } \\
\text { PB24D3.08c }\end{array}$ & 4.7 & cytosol [GO:0005829]; nucleus [GO:0005634] \\
\hline KIL86608.1 & NADH-cytochrome b5 reductase 1 & 4.6 & $\begin{array}{l}\text { endoplasmic reticulum membrane [GO:0005789]; integral } \\
\text { component of membrane [GO:0016021]; mitochondrial outer } \\
\text { membrane [GO:0005741] }\end{array}$ \\
\hline KIL94114.1 & Uncharacterized oxidoreductase TM_0019 & 2.7 & $\mathrm{NF}$ \\
\hline KIL83713.1 & Uncharacterized oxidoreductase DltE & 2.3 & cytoplasm [GO:0005737] \\
\hline KIL94143.1 & $\begin{array}{l}\text { FAD dependent oxidoreductase domain-containing } \\
\text { protein }\end{array}$ & 2.1 & integral component of membrane [GO:0016021] \\
\hline KIL95101.1 & Uncharacterized oxidoreductase $\mathrm{C} 4 \mathrm{H} 3.08$ & 2 & cytosol [GO:0005829]; nucleus [GO:0005634] \\
\hline KIL95944.1 & $\begin{array}{l}\text { External alternative } \mathrm{NAD}(\mathrm{P}) \mathrm{H} \text {-ubiquinone } \\
\text { oxidoreductase } \mathrm{B} 1 \text {, mitochondrial }\end{array}$ & 2 & $\begin{array}{l}\text { extrinsic component of mitochondrial inner membrane } \\
\text { [GO:0031314]; mitochondrial intermembrane space [GO:0005758]; } \\
\text { mitochondrion [GO:0005739]; peroxisome [GO:0005777] }\end{array}$ \\
\hline
\end{tabular}


TABLE 1 | Continued

\begin{tabular}{|c|c|c|c|}
\hline Transcript ID & $\begin{array}{l}\text { Gene name/ } \\
\text { function }\end{array}$ & $\begin{array}{l}\log _{2} \\
\text { (Fold change) }\end{array}$ & $\begin{array}{l}\text { Subcellular } \\
\text { localization }\end{array}$ \\
\hline & Organic Acids & & \\
\hline KIL86435.1 & Malic acid transport protein & 2.5 & $\begin{array}{l}\text { endoplasmic reticulum [GO:0005783]; integral component of } \\
\text { membrane [GO:0016021] }\end{array}$ \\
\hline KIL87976.1 & 2-methylisocitrate lyase, mitochondrial & 2 & mitochondrial matrix [GO:0005759] \\
\hline
\end{tabular}

Differentially expressed genes were filtered to those with $\log _{2}$ (fold change) $\geq 2$. Subcellular localization is given based on gene ontology. NF $=$ not found.

average diameter of $6.4 \mathrm{~cm}$. Activity of polyphenol oxidase (PPO) was increased in the caryopses exposed to F.a.1, however, PPO activity was not influenced by addition of $\mathrm{Al}$ (Figure 2).

\section{Fungal Genes Involved in Wild Oat Caryopsis Colonization}

In the absence of $\mathrm{Al}, 8,249$ genes were co-expressed in the fungus with (FW) or without the caryopses (FOW). In the presence or absence of the caryopses, 154 and 203 genes were uniquely expressed in the fungus (Figure 3A). Of uniquely expressed genes in the FW treatment, differentially expressed genes were associated with unique gene ontology terms; these terms included oxidation-reduction process, oxidoreductase activity, ion binding, small molecule binding, organic cyclic compound metabolic process, and more (Supplementary Table S7). Induction and repression of genes related to several biological functions were associated with $A$. fatua caryopsis colonization in the FW treatment, including genes involved in virulence/pathogenicity, stress detoxification responses, organic acid metabolism, metal interactions, basic metabolism, and amino acid/peptide/protein metabolism (Tables 1, 2, and Supplementary Table S1). Proteins of many of the induced and repressed genes were localized in various membrane compartments (Tables 1, 2), with several induced uncharacterized transporters being potentially localized to the vacuole membrane (Table 1).

\section{Fungal Genes Involved in Wild Oat Caryopsis Colonization During Aluminum Exposure}

Compared with the control, $\mathrm{Al}$ exposure led to slightly fewer genes $(8,067)$ being co-expressed in the fungus with (FA) or without the caryopses (FOA). In the FA and FOA treatments, 101 and 363 genes were uniquely expressed in the fungus, respectively (Figure 3B). Of uniquely expressed genes in the FA treatment, differentially expressed genes were associated with transporter activity (Supplementary Table S7). In the FOW treatment, 66 gene ontology terms were unique compared with the FW treatment, including primary metabolic process, macromolecule metabolic process, nitrogen compound metabolic process, cellular aromatic compound metabolic process, cellular nitrogen compound metabolic process, and more (Supplementary Table S7).

Genes related to several biological functions were differentially expressed during A. fatua caryopsis colonization and Al exposure (FA), including genes involved in iron metabolism, stress/defense responses, basic metabolism, metal-related responses, and amino acid/peptide/protein metabolism, and phosphate-related metabolism (Tables 3, 4 and Supplementary Table S1). While

TABLE 2 | Caryopsis-repressed differentially expressed genes in F. avenaceum F.a.1. in the absence of aluminum (FW vs. FOW).

\begin{tabular}{|c|c|c|c|}
\hline Transcript ID & Gene name/function & $\log _{2}$ (Fold change) & Subcellular localization \\
\hline & Development & & \\
\hline KIL95720.1 & Protein fluG & -2.2 & cytoplasm [GO:0005737] \\
\hline \multirow[t]{2}{*}{ KIL88384.1 } & Cell surface protein mas 1 & -2 & NF \\
\hline & Transport & & \\
\hline KIL94396.1 & Uncharacterized transporter YIL166C & -3.5 & $\begin{array}{l}\text { cell periphery [GO:0071944]; fungal-type vacuole [GO:0000324]; integral } \\
\text { component of plasma membrane [GO:0005887]; intrinsic component of } \\
\text { membrane [GO:0031224]; membrane [G0:0016020] }\end{array}$ \\
\hline \multirow[t]{2}{*}{ KIL94330.1 } & Putative metal chaperone YciC & -3.4 & NF \\
\hline & Cell wall-related & & \\
\hline KIL88383.1 & Bnr repeat-containing glycosyl hydrolase & -2.9 & NF \\
\hline \multirow[t]{2}{*}{ KIL85999.1 } & Probable endo-beta-1,4-glucanase D & -2.1 & extracellular region [GO:0005576] \\
\hline & Virulence & & \\
\hline KIL88379.1 & Secreted protein & -4.4 & NF \\
\hline KIL88377.1 & Secreted protein & -4 & NF \\
\hline KIL90234.1 & bys 1 protein & -2.2 & NF \\
\hline
\end{tabular}

Differentially expressed genes were filtered to those with $\log _{2}($ fold change) $\leq-2$. Subcellular localization is given based on gene ontology. NF $=$ not found. 
TABLE 3 | Caryopsis-induced differentially expressed genes in F. avenaceum F.a.1, during aluminum exposure (FA vs. FOA).

\begin{tabular}{|c|c|c|c|}
\hline Transcript ID & $\begin{array}{l}\text { Gene name/ } \\
\text { function }\end{array}$ & $\begin{array}{l}\log _{2} \\
\text { (Fold change) }\end{array}$ & Subcellular localization \\
\hline & Virulence & & \\
\hline KIL88590.1 & Polyketide synthase PksJ & 4.3 & cytoplasm [GO:0005737] \\
\hline KIL85362.1 & Ga4 desaturase & 3.5 & NF \\
\hline KIL84112.1 & Fumitremorgin C synthase & 3.4 & integral component of membrane [GO:0016021] \\
\hline KIL83610.1 & $\begin{array}{l}\text { NAD/NADP-dependent betaine aldehyde } \\
\text { dehydrogenase }\end{array}$ & 3.3 & NF \\
\hline KIL86378.1 & Nonribosomal peptide synthetase 8 & 3.2 & NF \\
\hline KIL90808.1 & Monooxygenase af470 & 2.9 & integral component of membrane [GO:0016021] \\
\hline KIL86961.1 & Phenolic acid decarboxylase padc & 2.8 & $\mathrm{NF}$ \\
\hline KIL86088.1 & O-methylsterigmatocystin oxidoreductase & 2.7 & NF \\
\hline KIL85314.1 & Copper amine oxidase 1 & 2.5 & NF \\
\hline KIL95831.1 & Global transcription regulator sge 1 & 2.5 & nucleus [GO:0005634] \\
\hline KIL87709.1 & Small secreted protein & 2.2 & NF \\
\hline KIL89840.1 & Acyl-CoA dehydrogenase & 2.2 & plasma membrane [GO:0005886] \\
\hline KIL89103.1 & Catalase-1 & 2.1 & $\begin{array}{l}\text { ascospore wall [GO:0005619]; cytosol [GO:0005829]; } \\
\text { extracellular region [GO:0005576] }\end{array}$ \\
\hline \multirow[t]{2}{*}{ KIL86331.1 } & $\begin{array}{l}\text { Related to OrfH-unknown, trichothecene gene } \\
\text { cluster }\end{array}$ & 2 & $\mathrm{NF}$ \\
\hline & Detoxification/Stress & & \\
\hline KIL88862.1 & Uncharacterized transporter C36.03c & 4.3 & $\begin{array}{l}\text { endoplasmic reticulum [GO:0005783]; fungal-type vacuole } \\
\text { [GO:0000324]; fungal-type vacuole membrane } \\
\text { [GO:0000329]; integral component of plasma membrane } \\
\text { [GO:0005887]; plasma membrane [GO:0005886] }\end{array}$ \\
\hline KIL95553.1 & Glutathione-independent glyoxalase HSP31 & 3.9 & $\begin{array}{l}\text { cytoplasmic stress granule [GO:0010494]; P-body } \\
\text { [GO:0000932] }\end{array}$ \\
\hline KIL84900.1 & Activator of stress genes 1 & 3.5 & nucleus [GO:0005634] \\
\hline KIL86249.1 & Pisatin demethylase & 2.8 & NF \\
\hline KIL86788.1 & Aldehyde dehydrogenase & 2.5 & $\mathrm{NF}$ \\
\hline KIL95994.1 & $\begin{array}{l}\text { Uncharacterized MFS-type transporter } \\
\text { C1271.10c }\end{array}$ & 2.5 & $\begin{array}{l}\text { cell cortex [GO:0005938]; integral component of plasma } \\
\text { membrane [GO:0005887] }\end{array}$ \\
\hline KIL87621.1 & Nitrosoguanidine resistance protein sng1 & 2.3 & integral component of membrane [GO:0016021] \\
\hline KIL88711.1 & Csbd-like domain-containing protein & 2.2 & $\mathrm{NF}$ \\
\hline KIL85820.1 & Uncharacterized transporter C794.04c & 2.2 & $\begin{array}{l}\text { fungal-type vacuole membrane [GO:0000329]; integral } \\
\text { component of plasma membrane [GO:0005887]; plasma } \\
\text { membrane [GO:0005886] }\end{array}$ \\
\hline KIL86151.1 & Brefeldin A resistance protein & 2.2 & $\begin{array}{l}\text { integral component of membrane [GO:0016021]; plasma } \\
\text { membrane [GO:0005886] }\end{array}$ \\
\hline \multirow[t]{2}{*}{ KIL96267.1 } & Acyl-CoA dehydrogenase family member 10 & 2 & mitochondrion [GO:0005739] \\
\hline & Siderophore & & \\
\hline \multirow[t]{2}{*}{ KIL86380.1 } & Nonribosomal peptide synthetase 4 (sidD) & 3.8 & cytoplasm [GO:0005737] \\
\hline & Iron-related & & \\
\hline KIL88164.1 & NADH-cytochrome b5 reductase 1 & 5.4 & $\begin{array}{l}\text { endoplasmic reticulum membrane [GO:0005789]; integral } \\
\text { component of membrane [GO:0016021]; mitochondrial } \\
\text { outer membrane [GO:0005741] }\end{array}$ \\
\hline \multirow[t]{2}{*}{ KIL90643.1 } & Bifunctional P-450:NADPH-P450 reductase & 3.7 & membrane [GO:0016020] \\
\hline & Oxidoreduction & & \\
\hline KIL87958.1 & $\begin{array}{l}\text { Zinc-type alcohol dehydrogenase-like protein } \\
\text { PB24D3.08c }\end{array}$ & 6 & cytosol [GO:0005829]; nucleus [GO:0005634] \\
\hline KIL94143.1 & $\begin{array}{l}\text { FAD dependent oxidoreductase } \\
\text { domain-containing protein }\end{array}$ & 3.3 & integral component of membrane [GO:0016021] \\
\hline KIL93076.1 & Uncharacterized oxidoreductase C736.13 & 2.8 & $\mathrm{NF}$ \\
\hline KIL83713.1 & Uncharacterized oxidoreductase DItE & 1.9 & cytoplasm [GO:0005737] \\
\hline
\end{tabular}


TABLE 3 | Continued

\begin{tabular}{llcl}
\hline Transcript ID & $\begin{array}{l}\text { Gene name/ } \\
\text { function }\end{array}$ & $\begin{array}{c}\text { Log }_{2} \\
\text { (Fold change) }\end{array}$ & Subcellular localization \\
\hline KIL88359.1 & Cell wall-related & & \\
KIL88726.1 & LysM domain-containing protein ARB_05157 & 3.4 & extracellular region [GO:0005576] \\
KIL94232.1 & Glucan endo-1,3-beta-glucosidase A1 & 3 & extracellular region [GO:0005576] \\
KIL88795.1 & Glucan endo-1,3-beta-glucosidase A1 & 2.7 & cell wall [GO:0005618]; extracellular region [GO:0005576] \\
KIL86896.1 & Pectinesterase & 2.6 & extracellular region [GO:0005576] \\
KIL88211.1 & Beta-glucosidase & 2.4 & integral component of membrane [GO:0016021]
\end{tabular}

Differentially expressed genes were filtered to those with $\log _{2}($ fold change) $\geq 2$. Subcellular localization is given based on gene ontology. NF $=$ not found.

TABLE 4 | Caryopsis-repressed differentially expressed genes in F. avenaceum F.a.1, during aluminum exposure (FA vs. FOA).

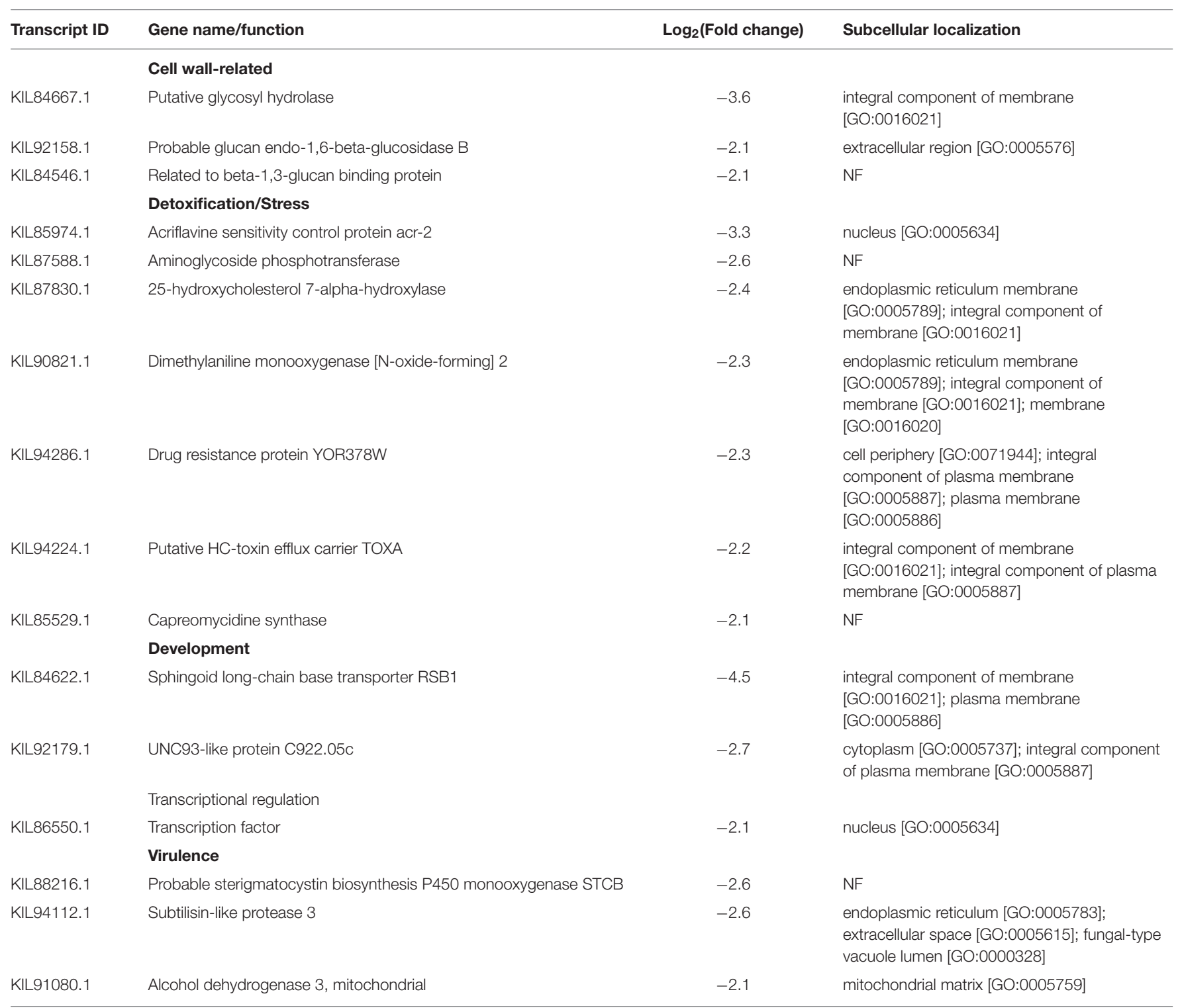

Differentially expressed genes were filtered to those with $\log _{2}($ fold change) $\geq 2$. Subcellular localization is given based on gene ontology. NF $=$ not found. 
TABLE 5 | Aluminum-induced differentially expressed genes in F. avenaceum F.a.1 during caryopsis colonization (FA vs. FW).

\begin{tabular}{|c|c|c|c|}
\hline Transcript ID & Gene name/function & $\log _{2}$ (Fold change) & Subcellular localization \\
\hline & Basic metabolism & & \\
\hline KIL85664.1 & Cytochrome b2, mitochondrial & 4.3 & $\begin{array}{l}\text { mitochondrial intermembrane space [GO:0005758]; respirasome } \\
\text { [GO:0070469] }\end{array}$ \\
\hline KIL88415.1 & D-xylose 1-dehydrogenase [NADP(+)] 2 & 3.6 & extracellular region [GO:0005576] \\
\hline KIL88271.1 & Glucokinase & 3.2 & cell [GO:0005623] \\
\hline KIL94987.1 & Uncharacterized methyltransferase C25B8.09 & 3.1 & cytosol [GO:0005829]; nucleus [GO:0005634] \\
\hline KIL86846.1 & Alkali-sensitive linkage protein 1 & 3 & $\begin{array}{l}\text { endoplasmic reticulum [GO:0005783]; external side of cell wall } \\
\text { [GO:0010339]; extracellular region [GO:0005576]; fungal-type cell } \\
\text { wall [GO:0009277]; Golgi apparatus [GO:0005794] }\end{array}$ \\
\hline KIL93784.1 & Cytoplasmic 60S subunit biogenesis factor REl1 homolog & 2.8 & cytoplasm [GO:0005737] \\
\hline KIL87652.1 & $\mathrm{NADH}$ oxidase & 2.7 & $\mathrm{NF}$ \\
\hline KIL87020.1 & $\begin{array}{l}\text { Enoyl-CoA hydratase domain-containing protein } 2 \text {, } \\
\text { mitochondrial }\end{array}$ & 2.5 & mitochondrion [GO:0005739] \\
\hline KIL85122.1 & putative mnn4-regulates the mannosylphosphorylation & 2.2 & integral component of membrane [GO:0016021] \\
\hline KIL94407.1 & $\begin{array}{l}\text { Uncharacterized CDP-alcohol phosphatidyltransferase } \\
\text { class-I family protein C22A12.08c }\end{array}$ & 2.1 & membrane [GO:0016020]; mitochondrion [GO:0005739] \\
\hline KIL94408.1 & Glycerol 2-dehydrogenase [NADP(+)] & 2.1 & NF \\
\hline KIL89558.1 & Glucose-repressible gene protein & 2 & NF \\
\hline \multirow[t]{2}{*}{ KIL89806.1 } & Phosphatidate phosphatase APP1 & 2 & actin cortical patch [GO:0030479] \\
\hline & Cell wall-related & & \\
\hline KIL87303.1 & Endopolygalacturonase AN8327 & 3.9 & extracellular region [GO:0005576] \\
\hline KIL88211.1 & Beta-glucosidase & 2.5 & integral component of membrane [GO:0016021] \\
\hline \multirow[t]{2}{*}{ KIL94677.1 } & Endochitinase B1 & 2.3 & extracellular region [GO:0005576] \\
\hline & Detoxification/Stress & & \\
\hline KIL93713.1 & Multidrug resistance-associated protein 1 & 8.4 & $\begin{array}{l}\text { basolateral plasma membrane [GO:0016323]; integral component } \\
\text { of membrane [GO:0016021]; membrane [GO:0016020] }\end{array}$ \\
\hline KIL86332.1 & Putative cytochrome P450 CYP13A7 & 4 & $\mathrm{NF}$ \\
\hline KIL88897.1 & Leptomycin B resistance protein pmd1 & 3.8 & $\begin{array}{l}\text { fungal-type vacuole [GO:0000324]; integral component of } \\
\text { membrane [GO:0016021]; plasma membrane [GO:0005886] }\end{array}$ \\
\hline KIL91637.1 & Multidrug resistance protein 2 & 2.8 & integral component of membrane [GO:0016021] \\
\hline \multirow[t]{2}{*}{ KIL88089.1 } & 4-sulfomuconolactone hydrolase & 2.3 & $\mathrm{NF}$ \\
\hline & Development & & \\
\hline KIL86107.1 & Dimethylaniline monooxygenase [N-oxide-forming] 5 & 4.7 & NF \\
\hline KIL90244.1 & Infection structure specific protein & 2.9 & NF \\
\hline \multirow[t]{2}{*}{ KIL90075.1 } & Uncharacterized FAD-linked oxidoreductase YvdP & 2.2 & spore wall [GO:0031160] \\
\hline & Oxidoreduction & & \\
\hline KIL87669.1 & Uncharacterized FAD-linked oxidoreductase ARB_02478 & 4.3 & extracellular region [GO:0005576] \\
\hline KIL95747.1 & Dimethyl-sulfide monooxygenase & 3.6 & NF \\
\hline KIL87414.1 & Isoamyl alcohol & 2.5 & $\mathrm{NF}$ \\
\hline \multirow[t]{2}{*}{ KIL88501.1 } & Uncharacterized FAD-linked oxidoreductase ARB_02478 & 2 & extracellular region [GO:0005576] \\
\hline & Transport & & \\
\hline KIL86435.1 & Malic acid transport protein & 3.3 & $\begin{array}{l}\text { endoplasmic reticulum [GO:0005783]; integral component of } \\
\text { membrane [GO:0016021] }\end{array}$ \\
\hline KIL86675.1 & Uncharacterized transporter PB1C11.03 & 3 & $\begin{array}{l}\text { endoplasmic reticulum [GO:0005783]; integral component of } \\
\text { plasma membrane [GO:0005887]; intrinsic component of } \\
\text { membrane [GO:0031224] }\end{array}$ \\
\hline KIL85821.1 & Uncharacterized membrane protein YJR124C & 2.9 & $\begin{array}{l}\text { fungal-type vacuole membrane [GO:0000329]; integral component } \\
\text { of plasma membrane [G0:0005887] }\end{array}$ \\
\hline KIL91580.1 & Iron transport multicopper oxidase FET3 & 2.8 & $\begin{array}{l}\text { cell [GO:0005623]; high-affinity iron permease complex } \\
\text { [GO:0033573] }\end{array}$ \\
\hline KIL93709.1 & Protein kes1 & 2.5 & $\begin{array}{l}\text { cell division site [GO:0032153]; cytosol [GO:0005829]; intracellular } \\
\text { membrane-bounded organelle [GO:0043231]; membrane } \\
\text { [GO:0016020] }\end{array}$ \\
\hline KIL93707.1 & P-type cation-transporting ATPase & 2.3 & $\begin{array}{l}\text { cell [GO:0005623]; integral component of plasma membrane } \\
\text { [GO:0005887]; plasma membrane [GO:0005886]; proteasome core } \\
\text { complex [GO:0005839] }\end{array}$ \\
\hline KIL87110.1 & Hexose transporter 2 & 2 & integral component of membrane [GO:0016021] \\
\hline
\end{tabular}


TABLE 5 | Continued

\begin{tabular}{|c|c|c|c|}
\hline Transcript ID & Gene name/function & $\log _{2}$ (Fold change) & Subcellular localization \\
\hline & Virulence & & \\
\hline KIL88898.1 & Apoptosis-inducing factor 2 & 8.6 & $\begin{array}{l}\text { cytoplasm [GO:0005737]; cytosol [GO:0005829]; integral } \\
\text { component of membrane [GO:0016021]; lipid droplet } \\
\text { [GO:0005811]; mitochondrial outer membrane [GO:0005741]; } \\
\text { mitochondrion [GO:0005739] }\end{array}$ \\
\hline KIL93640.1 & $\begin{array}{l}\text { L-ornithine N(5)-monooxygenase (Siderophore } \\
\text { Biosynthesis) }\end{array}$ & 6.3 & NF \\
\hline KIL94193.1 & Apoptosis-inducing factor 2 & 4.9 & $\begin{array}{l}\text { integral component of membrane [GO:0016021]; mitochondrial } \\
\text { outer membrane [GO:0005741] }\end{array}$ \\
\hline KIL84112.1 & Fumitremorgin C synthase & 4.7 & integral component of membrane [GO:0016021] \\
\hline KIL84938.1 & Endoglucanase-7 & 3.9 & extracellular region [GO:0005576] \\
\hline KIL93826.1 & Aspergillopepsin-2 & 2.8 & NF \\
\hline KIL93932.1 & Related to acetylxylan esterase & 2.5 & NF \\
\hline KIL85313.1 & Aldehyde dehydrogenase & 2.5 & cytoplasm [GO:0005737] \\
\hline KIL84075.1 & Peroxiredoxin-1 & 2.3 & cell [GO:0005623]; cytosol [GO:0005829]; nucleus [GO:0005634] \\
\hline
\end{tabular}

Differentially expressed genes were filtered to those with $\log _{2}$ (fold change) $\geq 2$. Subcellular localization is given based on gene ontology. NF $=$ not found.

TABLE 6 | Aluminum-repressed differentially expressed genes in F. avenaceum F.a.1 during caryopsis colonization (FA vs. FW).

\begin{tabular}{|c|c|c|c|}
\hline Transcript ID & Gene name/function & $\log _{2}$ (Fold change) & Subcellular localization \\
\hline & Basic metabolism & & \\
\hline KIL90295.1 & Probable quinate permease & -6 & integral component of plasma membrane [GO:0005887] \\
\hline KIL94775.1 & Fibronectin type III domain protein & -2.4 & $\mathrm{NF}$ \\
\hline KIL95538.1 & Protein SERAC1 & -2.3 & $\begin{array}{l}\text { endoplasmic reticulum [GO:0005783]; extracellular matrix } \\
\text { [GO:0031012]; integral component of membrane } \\
\text { [GO:0016021]; mitochondria-associated endoplasmic reticulum } \\
\text { membrane [GO:0044233]; mitochondrion [GO:0005739] }\end{array}$ \\
\hline KIL86771.1 & alpha beta-hydrolase & -2.1 & NF \\
\hline KIL89429.1 & $\begin{array}{l}\text { Uncharacterized PH domain-containing protein } \\
\text { YPR091C }\end{array}$ & -2 & $\begin{array}{l}\text { cell periphery [GO:0071944]; endoplasmic reticulum } \\
\text { [GO:0005783]; endoplasmic reticulum membrane } \\
\text { [GO:0005789]; integral component of membrane } \\
\text { [GO:0016021]; nucleus-vacuole junction [GO:0071561] }\end{array}$ \\
\hline \multirow[t]{2}{*}{ KIL90108.1 } & Alpha-glucosidase & -2 & cytosol [GO:0005829]; nucleus [GO:0005634] \\
\hline & Detoxification/Stress & & \\
\hline KIL89371.1 & Ent-kaurene oxidase & -8.5 & integral component of membrane [GO:0016021] \\
\hline KIL88204.1 & Phenol 2-monooxygenase & -7 & NF \\
\hline KIL84575.1 & Peroxisomal catalase & -4.2 & fungal-type cell wall [GO:0009277]; peroxisome [GO:0005777] \\
\hline KIL88419.1 & Glutathione reductase & -2.9 & $\begin{array}{l}\text { cell [GO:0005623]; cytosol [GO:0005829]; mitochondrion } \\
\text { [GO:0005739]; nucleus [GO:0005634] }\end{array}$ \\
\hline KIL94286.1 & Drug resistance protein YOR378W & -2.6 & $\begin{array}{l}\text { cell periphery [GO:0071944]; integral component of plasma } \\
\text { membrane [GO:0005887]; plasma membrane [GO:0005886] }\end{array}$ \\
\hline KIL87830.1 & 25-hydroxycholesterol 7-alpha-hydroxylase & -2.5 & $\begin{array}{l}\text { endoplasmic reticulum membrane [GO:0005789]; integral } \\
\text { component of membrane [G0:0016021] }\end{array}$ \\
\hline KIL93328.1 & DNA damage response protein kinase DUN1 & -2.3 & cytoplasm [GO:0005737]; nucleus [GO:0005634] \\
\hline KIL83874.1 & Probable nitronate monooxygenase & -2.1 & NF \\
\hline KIL84602.1 & HET-domain-containing protein & -2 & NF \\
\hline \multirow[t]{2}{*}{ KIL93910.1 } & Cytochrome P450 1A1 & -2 & endoplasmic reticulum membrane [GO:0005789] \\
\hline & Development & & \\
\hline KIL88563.1 & Vegetative incompatibility protein HET-E-1 & -3 & NF \\
\hline KIL90704.1 & Vegetative incompatibility protein HET-E-1 & -2.7 & NF \\
\hline KIL88384.1 & cell surface protein mas1 [Fusarium langsethiae] & -2.7 & NF \\
\hline KIL90265.1 & Vegetative incompatibility protein HET-E-1 & -2.6 & NF \\
\hline KIL92404.1 & Vegetative incompatibility protein HET-E-1 & -2.2 & NF \\
\hline KIL86170.1 & Vegetative incompatibility protein HET-E-1 & -2.1 & NF \\
\hline
\end{tabular}


TABLE 6 | Continued

\begin{tabular}{|c|c|c|c|}
\hline Transcript ID & Gene name/function & $\log _{2}$ (Fold change) & Subcellular localization \\
\hline \multirow[t]{2}{*}{ KIL83903.1 } & Vegetative incompatibility protein HET-E-1 & -2 & NF \\
\hline & Nitrate assimilation & & \\
\hline \multirow[t]{2}{*}{ KIL84574.1 } & Sulfite oxidase, mitochondrial & -3.8 & $\begin{array}{l}\text { mitochondrial intermembrane space [GO:0005758]; } \\
\text { mitochondrial matrix [GO:0005759]; mitochondrion } \\
\text { [GO:0005739] }\end{array}$ \\
\hline & Oxidoreduction & & \\
\hline \multirow[t]{2}{*}{ KIL89100.1 } & UDP-N-acetyl-D-glucosamine 6-dehydrogenase & -2.4 & integral component of membrane [GO:0016021] \\
\hline & Transcriptional regulation & & \\
\hline \multirow[t]{2}{*}{ KIL90031.1 } & Transcription factor & -2 & nucleus [GO:0005634] \\
\hline & Transport & & \\
\hline KIL85428.1 & Bypass of stop codon protein 6 & -2.4 & $\begin{array}{l}\text { Golgi apparatus [GO:0005794]; integral component of plasma } \\
\text { membrane [GO:0005887]; membrane [GO:0016020] }\end{array}$ \\
\hline KIL89987.1 & $\begin{array}{l}\text { Uncharacterized ABC transporter ATP-binding } \\
\text { protein/permease YOL075C }\end{array}$ & -2.3 & $\begin{array}{l}\text { cell periphery [GO:0071944]; fungal-type vacuole membrane } \\
\text { [GO:0000329]; integral component of membrane [GO:0016021] }\end{array}$ \\
\hline KIL94326.1 & Vacuolar iron transporter 1.2 & -2.3 & $\mathrm{NF}$ \\
\hline KIL90349.1 & $\begin{array}{l}\text { Sodium/potassium-transporting ATPase subunit } \\
\text { alpha }\end{array}$ & -2.1 & $\begin{array}{l}\text { integral component of membrane [GO:0016021]; plasma } \\
\text { membrane [GO:0005886] }\end{array}$ \\
\hline KIL84309.1 & $\begin{array}{l}\text { Probable inactive } \\
\text { 1-aminocyclopropane-1-carboxylate synthase-like } \\
\text { protein } 2\end{array}$ & -2.1 & $\mathrm{NF}$ \\
\hline \multirow[t]{2}{*}{ KIL91916.1 } & Uncharacterized transporter $\mathrm{C} 3 \mathrm{H} 1.06 \mathrm{c}$ & -2 & $\begin{array}{l}\text { endoplasmic reticulum [GO:0005783]; integral component of } \\
\text { membrane [GO:0016021]; integral component of plasma } \\
\text { membrane [GO:0005887] }\end{array}$ \\
\hline & Virulence & & \\
\hline KIL86397.1 & $\begin{array}{l}\text { Conidial yellow pigment biosynthesis polyketide } \\
\text { synthase }\end{array}$ & -4.4 & NF \\
\hline KIL87828.1 & Nonribosomal peptide synthetase 8 & -2.7 & NF \\
\hline KIL89330.1 & Versicolorin B synthase & -2.7 & cytosol [GO:0005829] \\
\hline KIL89340.1 & Fumitremorgin C synthase & -2.3 & $\begin{array}{l}\text { cytoplasm [GO:0005737]; integral component of membrane } \\
\text { [GO:0016021]; intracellular membrane-bounded organelle } \\
\text { [GO:0043231] }\end{array}$ \\
\hline KIL93322.1 & Laccase-2 & -2 & extracellular region [GO:0005576] \\
\hline
\end{tabular}

Differentially expressed genes were filtered to those with $\log _{2}$ (Fold Change) $\leq-2$. Subcellular localization is given based on gene ontology. NF = not found.

many of the induced and repressed genes were found to encode proteins potentially localized in cellular membranes, several of the induced cell wall-related genes were found to be localized in the extracellular region (Tables 3, 4).

\section{The Influence of Al on Caryopsis Colonization}

Caryopsis colonization resulted in co-expression of 8,026 genes in the fungus exposed to water (FW) or Al (FA). Additionally, 142 and 377 genes were uniquely expressed in the fungus in the presence or absence of $\mathrm{Al}$, respectively (Figure 3C). Compared with the FW treatment, uniquely expressed DEGs were associated with three unique gene ontology terms in the FA treatment, including cofactor binding, coenzyme binding, and ion transport (Supplementary Table S7).

Induction of genes related to several biological functions were associated with $\mathrm{Al}$ exposure during $A$. fatua caryopsis colonization (FA) when compared to the FW treatment, including genes involved in siderophore metabolism, iron metabolism, stress/defense responses, drug resistance, basic metabolism, metal-related responses, and phosphate-related metabolism (Tables 5, 6 and Supplementary Table S1). Proteins of both Al-repressed and Al-induced genes were found to be potentially localized to membranes and the cytosol/cytoplasm (Tables 5, 6). Two genes associated with transport and detoxification (uncharacterized membrane protein YJR124C and leptomycin B resistance protein pmd1, respectively), were found to be induced by $\mathrm{Al}$, with the associated proteins potentially being localized in the vacuole membrane (Table 5). Laccase-2 was found to be repressed by $\mathrm{Al}$ in the FA treatment compared to the FW treatment, and was found to be potentially partitioned to the extracellular region (Table 6).

\section{Fungal Transcriptomic Responses to Aluminum Exposure}

Exposure of F.a.1 to $\mathrm{Al}$ (FOA) or water (FOW) resulted in the co-expression of 8,204 genes in the absence of caryopses (Figure 3D). In the FOW treatment, 248 genes were uniquely expressed, while 226 genes were uniquely expressed during $\mathrm{Al}$ exposure (FOA). Genes uniquely expressed in the FOA treatment compared with FOW, were associated with 33 unique GO terms, including several protein-related GO terms, 
TABLE 7 | Aluminum-induced differentially expressed genes in F. avenaceum F.a.1, in the absence of caryopsis colonization (FOA vs. FOW).

\begin{tabular}{|c|c|c|c|}
\hline Transcript ID & Gene name/function & $\log _{2}$ (Fold change) & Subcellular localization \\
\hline & Siderophore-related & & \\
\hline KIL93715.1 & Nonribosomal peptide synthetase 2 & 9.1 & cell [GO:0005623]; cytoplasm [GO:0005737] \\
\hline KIL94141.1 & Siderophore iron transporter mirB & 8.8 & $\begin{array}{l}\text { cell [GO:0005623]; integral component of plasma membrane } \\
\text { [GO:0005887] }\end{array}$ \\
\hline KIL85942.1 & Siderophore iron transporter mirB & 7.8 & $\begin{array}{l}\text { cell [GO:0005623]; integral component of plasma membrane } \\
\text { [GO:0005887] }\end{array}$ \\
\hline KIL93640.1 & L-ornithine N(5)-monooxygenase & 6.7 & NF \\
\hline KIL93714.1 & Putative lysine N-acyltransferase C17G9.06c & 6.2 & cytosol [GO:0005829]; nucleus [GO:0005634] \\
\hline KIL87671.1 & Nonribosomal peptide synthetase 4 & 6 & $\mathrm{NF}$ \\
\hline KIL95063.1 & Siderophore iron transporter mirB & 5.9 & $\begin{array}{l}\text { cell [GO:0005623]; integral component of plasma membrane } \\
\text { [GO:0005887] }\end{array}$ \\
\hline KIL87674.1 & Siderophore iron transporter mirB & 5.8 & $\begin{array}{l}\text { cell [GO:0005623]; integral component of plasma membrane } \\
\text { [GO:0005887] }\end{array}$ \\
\hline KIL87673.1 & Putative lysine N-acyltransferase C17G9.06c & 5.1 & cytosol [GO:0005829]; nucleus [GO:0005634] \\
\hline KIL93712.1 & Siderophore iron transporter 3 & 4.3 & $\begin{array}{l}\text { cell [GO:0005623]; cytoplasm [GO:0005737]; integral component of } \\
\text { membrane [GO:0016021]; integral component of plasma membrane } \\
\text { [GO:0005887]; plasma membrane [GO:0005886] }\end{array}$ \\
\hline KIL92195.1 & Siderophore iron transporter mirA & 3.9 & integral component of plasma membrane [GO:0005887] \\
\hline KIL85295.1 & Siderophore iron transporter 1 & 3.4 & $\begin{array}{l}\text { cell [GO:0005623]; cytoplasmic vesicle [GO:0031410]; endosome } \\
\text { [GO:0005768]; endosome membrane [GO:0010008]; fungal-type vacuole } \\
\text { [GO:0000324]; integral component of plasma membrane [GO:0005887]; } \\
\text { plasma membrane [GO:0005886]; vacuolar membrane [GO:0005774] }\end{array}$ \\
\hline KIL88899.1 & Putative lysine N-acyltransferase C17G9.06c & 2.6 & cytosol [GO:0005829]; nucleus [GO:0005634] \\
\hline \multirow[t]{2}{*}{ KIL93180.1 } & Siderophore biosynthesis & 2.2 & $\mathrm{NF}$ \\
\hline & Iron-related & & \\
\hline KIL87675.1 & Ferri-bacillibactin esterase BesA & 6.1 & cytoplasm [GO:0005737] \\
\hline KIL94023.1 & Peroxisomal catalase & 5 & peroxisome [GO:0005777] \\
\hline KIL94226.1 & 1,3-propanediol dehydrogenase & 3.5 & NF \\
\hline KIL91581.1 & Plasma membrane iron permease & 2.8 & $\begin{array}{l}\text { high-affinity iron permease complex [GO:0033573]; plasma membrane } \\
\text { [GO:0005886] }\end{array}$ \\
\hline KIL93711.1 & Ferric reductase transmembrane component 5 & 2.3 & $\begin{array}{l}\text { cell [GO:0005623]; integral component of membrane [GO:0016021]; } \\
\text { mitochondrion [GO:0005739]; plasma membrane [GO:0005886] }\end{array}$ \\
\hline KIL86612.1 & Plasma membrane iron permease & 2.3 & $\begin{array}{l}\text { cell [GO:0005623]; endoplasmic reticulum [GO:0005783]; Golgi } \\
\text { apparatus [GO:0005794]; high-affinity iron permease complex } \\
\text { [GO:0033573]; plasma membrane [GO:0005886] }\end{array}$ \\
\hline \multirow[t]{2}{*}{ KIL86611.1 } & Iron transport multicopper oxidase FET3 & 2.3 & $\begin{array}{l}\text { cell [GO:0005623]; endoplasmic reticulum [GO:0005783]; fungal-type } \\
\text { vacuole [GO:0000324]; high-affinity iron permease complex } \\
\text { [GO:0033573]; plasma membrane [GO:0005886] }\end{array}$ \\
\hline & Organic acid-related & & \\
\hline KIL86435.1 & Malic acid transport protein & 4 & $\begin{array}{l}\text { endoplasmic reticulum [GO:0005783]; integral component of membrane } \\
\text { [GO:0016021] }\end{array}$ \\
\hline KIL87894.1 & Oxalate decarboxylase OxdD & 3.7 & cytoplasm [GO:0005737] \\
\hline KIL96152.1 & Isocitrate lyase & 2.3 & glyoxysome [GO:0009514] \\
\hline KIL87976.1 & 2-methylisocitrate lyase, mitochondrial & 2.3 & mitochondrial matrix [GO:0005759] \\
\hline KIL84732.1 & Mitochondrial oxaloacetate transport protein & 2 & $\begin{array}{l}\text { integral component of membrane [GO:0016021]; mitochondrial inner } \\
\text { membrane [GO:0005743]; mitochondrion [GO:0005739] }\end{array}$ \\
\hline
\end{tabular}

Differentially expressed genes were filtered to those with $\log _{2}$ (Fold Change) $\geq 2$. Subcellular localization is given based on gene ontology. NF $=$ not found.

ion transport, organic substance transport, organonitrogen compound metabolic process, organic acid transport, and more (Supplementary Table S7). Compared with the FOA treatment, the FOW treatment was associated with 22 unique GO terms, including several related to nucleic acid metabolism, carbohydrate derivative binding, lipid biosynthetic processes, ATP binding, iron ion binding, oxidoreductase activity (acting on $\mathrm{CH}-\mathrm{OH}$ group donors, and more) (Supplementary Table S7).
Additionally, $\mathrm{Al}$ exposure led to induction of several genes associated with siderophore transport, iron metabolism, organic acid metabolism, and metals, as well as, genes associated with stress /defense, and drug resistance (Tables 7-9 and Supplementary Table S1). Proteins of most of the induced siderophore-related genes were found to be potentially localized to various membranes throughout the cell (Tables 7, 8). Siderophore iron transporter 3 was found to potentially be 
TABLE 8 | Additional aluminum-induced differentially expressed genes in F. avenaceum F.a.1, in the absence of caryopsis colonization (FOA vs. FOW).

\begin{tabular}{|c|c|c|c|}
\hline Transcript ID & Gene name/function & $\log _{2}$ (Fold change) & Subcellular localization \\
\hline & Virulence & & \\
\hline KIL88898.1 & Apoptosis-inducing factor 2 & 8.4 & $\begin{array}{l}\text { cytoplasm [GO:0005737]; cytosol [GO:0005829]; integral } \\
\text { component of membrane [GO:0016021]; lipid droplet } \\
\text { [GO:0005811]; mitochondrial outer membrane } \\
\text { [GO:0005741]; mitochondrion [G0:0005739] }\end{array}$ \\
\hline KIL94193.1 & Apoptosis-inducing factor 2 & 6.4 & $\begin{array}{l}\text { integral component of membrane [GO:0016021]; } \\
\text { mitochondrial outer membrane [GO:0005741] }\end{array}$ \\
\hline KIL85313.1 & Aldehyde dehydrogenase & 4.6 & cytoplasm [GO:0005737] \\
\hline KIL94858.1 & Acetyl-coenzyme A synthetase & 3.3 & extracellular region [GO:0005576] \\
\hline KIL88588.1 & Bys1 protein & 3.3 & $\mathrm{NF}$ \\
\hline KIL88216.1 & $\begin{array}{l}\text { Probable sterigmatocystin biosynthesis P450 } \\
\text { monooxygenase STCB }\end{array}$ & 3 & NF \\
\hline KIL86239.1 & Nonribosomal peptide synthetase 1 & 2.9 & cytoplasm [GO:0005737] \\
\hline KIL93826.1 & Aspergillopepsin-2 & 2.9 & NF \\
\hline KIL90137.1 & Related to cornifin B & 2.9 & NF \\
\hline KIL87701.1 & Related to 2'-hydroxyisoflavone reductase & 2.8 & $\mathrm{NF}$ \\
\hline KIL85408.1 & Alcohol dehydrogenase [NADP $(+)]$ & 2.8 & $\begin{array}{l}\text { apical plasma membrane [GO:0016324]; cytosol } \\
\text { [GO:0005829]; synapse [GO:0045202] }\end{array}$ \\
\hline KIL84075.1 & Peroxiredoxin-1 & 2.6 & $\begin{array}{l}\text { cell [GO:0005623]; cytosol [GO:0005829]; nucleus } \\
\text { [GO:0005634] }\end{array}$ \\
\hline KIL88365.1 & Phosphatidylglycerol lysyltransferase & 2.6 & NF \\
\hline KIL84112.1 & Fumitremorgin C synthase & 2.5 & integral component of membrane [GO:0016021] \\
\hline KIL92157.1 & Acetyl-CoA hydrolase & 2.5 & mitochondrion [GO:0005739] \\
\hline KIL95012.1 & Related to secretory lipase & 2.5 & NF \\
\hline KIL87715.1 & $\mathrm{N}$-acyl homoserine lactonase attm & 2.5 & NF \\
\hline KIL86939.1 & Necrosis-inducing protein & 2.5 & NF \\
\hline KIL94006.1 & Laccase ARB_05828 & 2.4 & extracellular region [GO:0005576] \\
\hline KIL93932.1 & Related to acetylxylan esterase & 2.4 & $\mathrm{NF}$ \\
\hline KIL94112.1 & Subtilisin-like protease 3 & 2.3 & $\begin{array}{l}\text { endoplasmic reticulum [GO:0005783]; extracellular space } \\
\text { [GO:0005615]; fungal-type vacuole lumen [GO:0000328] }\end{array}$ \\
\hline KIL96580.1 & Infection structure specific protein & 2.2 & NF \\
\hline KIL89564.1 & Putative aldehyde dehydrogenase-like protein YHR039C & 2.1 & endoplasmic reticulum [GO:0005783] \\
\hline KIL92119.1 & Related to cornifin B & 2.1 & $\mathrm{NF}$ \\
\hline KIL84683.1 & $\begin{array}{l}\text { RecName: Full = Loline biosynthesis cluster } 1 \text { transcription } \\
\text { factor lolU1 }\end{array}$ & 2.1 & nucleus [GO:0005634] \\
\hline \multirow[t]{2}{*}{ KIL92927.1 } & $\begin{array}{l}\text { Putative branched-chain-amino-acid aminotransferase } \\
\text { TOXF }\end{array}$ & 2 & NF \\
\hline & Detoxification/Stress & & \\
\hline KIL92628.1 & Uncharacterized MFS-type transporter C409.08 & 7.9 & $\begin{array}{l}\text { fungal-type vacuole membrane [GO:0000329]; integral } \\
\text { component of plasma membrane [GO:0005887]; plasma } \\
\text { membrane [GO:0005886] }\end{array}$ \\
\hline KIL93713.1 & Multidrug resistance-associated protein 1 & 7.6 & $\begin{array}{l}\text { basolateral plasma membrane [GO:0016323]; integral } \\
\text { component of membrane [GO:0016021]; membrane } \\
\text { [GO:0016020] }\end{array}$ \\
\hline KIL88411.1 & Aflatoxin B1 aldehyde reductase member 4 & 7 & $\begin{array}{l}\text { cytosol [GO:0005829]; extracellular exosome } \\
\text { [GO:0070062] }\end{array}$ \\
\hline KIL90653.1 & Probable formaldehyde dehydrogenase AdhA & 5.6 & $\mathrm{NF}$ \\
\hline KIL85974.1 & Acriflavine sensitivity control protein acr-2 & 4.6 & nucleus [GO:0005634] \\
\hline KIL88897.1 & Leptomycin B resistance protein pmd1 & 4.4 & $\begin{array}{l}\text { fungal-type vacuole [GO:0000324]; integral component of } \\
\text { membrane [GO:0016021]; plasma membrane } \\
\text { [GO:0005886] }\end{array}$ \\
\hline KIL86332.1 & Putative cytochrome P450 CYP13A7 & 4 & $\mathrm{NF}$ \\
\hline KIL93695.1 & Isotrichodermin C-15 hydroxylase & 3.9 & integral component of membrane [GO:0016021] \\
\hline KIL84891.1 & NADH-cytochrome b5 reductase 2 & 3.8 & $\begin{array}{l}\text { integral component of mitochondrial outer membrane } \\
\text { [GO:0031307]; mitochondrial intermembrane space } \\
\text { [GO:0005758] }\end{array}$ \\
\hline KIL87621.1 & Nitrosoguanidine resistance protein sng1 & 3.4 & integral component of membrane [GO:0016021] \\
\hline
\end{tabular}


TABLE 8 | Continued

\begin{tabular}{|c|c|c|c|}
\hline Transcript ID & Gene name/function & $\log _{2}$ (Fold change) & Subcellular localization \\
\hline KIL88089.1 & 4-sulfomuconolactone hydrolase & 3.3 & $\mathrm{NF}$ \\
\hline KIL91637.1 & Multidrug resistance protein 2 & 3.3 & integral component of membrane [GO:0016021] \\
\hline KIL86787.1 & Aldehyde dehydrogenase & 3 & extracellular region [GO:0005576] \\
\hline KIL94192.1 & Ethyl tert-butyl ether degradation ethd & 2.5 & NF \\
\hline KIL87482.1 & Pyrethroid hydrolase & 2.4 & $N F$ \\
\hline KIL84681.1 & Putative HC-toxin efflux carrier TOXA & 2.3 & $\begin{array}{l}\text { integral component of membrane [GO:0016021]; integral } \\
\text { component of plasma membrane [GO:0005887] }\end{array}$ \\
\hline KIL94406.1 & (S)-2-haloacid dehalogenase $\mathrm{H}$-109 & 2.2 & $\mathrm{NF}$ \\
\hline KIL84854.1 & $\begin{array}{l}\text { Tetracycline resistance protein from transposon } \\
\text { Tn4351/Tn4400 }\end{array}$ & 2.2 & cytoplasm [GO:0005737] \\
\hline KIL87757.1 & Nitrosoguanidine resistance protein & 2.2 & integral component of membrane [GO:0016021] \\
\hline KIL92588.1 & Quinidine resistance protein 2 & 2.1 & $\begin{array}{l}\text { cell periphery [GO:0071944]; integral component of plasma } \\
\text { membrane [GO:0005887]; plasma membrane } \\
\text { [GO:0005886] }\end{array}$ \\
\hline KIL88169.1 & Glutathione S-transferase PM239X14 & 2.1 & cytosol [GO:0005829] \\
\hline KIL96198.1 & Puromycin N-acetyltransferase & 2.1 & NF \\
\hline KIL86804.1 & Putative duf636 domain protein & 2.1 & NF \\
\hline KIL95076.1 & Heat shock protein 16 & 2.1 & $\begin{array}{l}\text { cytoplasm [GO:0005737]; cytosol [GO:0005829]; nucleus } \\
\text { [GO:0005634] }\end{array}$ \\
\hline KIL94213.1 & Multidrug resistance-associated protein 1 & 2 & $\begin{array}{l}\text { basolateral plasma membrane [GO:0016323]; integral } \\
\text { component of membrane [GO:0016021]; membrane } \\
\text { [GO:0016020] }\end{array}$ \\
\hline KIL93503.1 & Putative HC-toxin efflux carrier TOXA & 2 & $\begin{array}{l}\text { integral component of membrane [GO:0016021]; integral } \\
\text { component of plasma membrane [GO:0005887] }\end{array}$ \\
\hline
\end{tabular}

Differentially expressed genes were filtered to those with $\log _{2}$ (Fold Change) $\geq 2$. Subcellular localization is given based on gene ontology. NF $=$ not found.

localized to cell, cytoplasm, integral component of membrane, integral component of plasma membrane, and/or plasma membrane (Table 7). Siderophore iron transporter 1 was found to be potentially localized to any of several compartments, including cell, cytoplasmic vesicle, endosome, endosome membrane, fungal-type vacuole, integral component of plasma membrane, plasma membrane, and/or vacuolar membrane (Table 7). Several Al-induced virulence and detoxification genes were found to potentially encode for proteins that might partition to the extracellular space, including acetyl-coenzyme A synthetase, laccase ARB_05828, subtilisin-like protease 3, aflatoxin B1 aldehyde reductase member 4, and aldehyde dehydrogenase (Table 8).

\section{GENE ONTOLOGY (GO) ENRICHMENT AND KEGG (KYOTO ENCYCLOPEDIA OF GENES AND GENOMES) PATHWAY ANALYSIS}

\section{Chronic Aluminum Exposure Influences Gene Ontology Enrichment}

Chronic Exposure of F.a.1 to sublethal concentrations of $\mathrm{Al}$ (FOA) was associated with changes in the enrichment of many genes from ontology groups associated with biological and molecular processes. Aluminum exposure was related to induction of genes involved in biological and metabolic processes, catalytic activity, single-organism process, singleorganism metabolic process, oxidoreductase activity, oxidationreduction process, organonitrogen compound metabolic process, small molecule metabolic process, organonitrogen compound biosynthetic process, carboxylic acid metabolic process, oxoacid metabolic process, and organic acid metabolic process (Table 10). Aluminum exposure was also related to the repression of genes associated with gene ontology groups, including biological regulation, cation binding, regulation of cellular process, regulation of biological process, metal ion binding, transition metal ion binding, zinc ion binding, nucleic acid binding transcription factor activity, transcription factor activity, and sequence-specific DNA binding (Table 10). Repression was also observed of several iron-related genes in response to $\mathrm{Al}$ exposure. KEGG pathway analysis showed Al exposure led to induction of pathways associated with biosynthesis of secondary metabolites, biosynthesis of amino acids, carbon metabolism, 2-oxocarboxylic acid metabolism, cysteine and methionine metabolism, propanoate metabolism, lysine biosynthesis, and, valine, leucine and isoleucine degradation (Table 11).

\section{Gene Ontology Enrichment Is Influenced by Caryopsis Colonization During Aluminum Exposure}

Caryopsis colonization during aluminum exposure (FA) resulted in the induction of gene ontology terms associated with biological, cellular component, and molecular functions. These gene ontology terms were associated with some general biological 
TABLE 9 | Aluminum-repressed differentially expressed genes in F. avenaceum F.a.1 in the absence of caryopsis colonization (FOA vs. FOW).

\begin{tabular}{|c|c|c|c|}
\hline Transcript ID & Gene name/function & $\log _{2}$ (Fold change) & Subcellular localization \\
\hline & Iron-related & & \\
\hline KIL86453.1 & Cytochrome P450 52A13 & -5 & membrane [GO:0016020] \\
\hline KIL95759.1 & Psi-producing oxygenase A & -3.6 & $\mathrm{NF}$ \\
\hline KIL94326.1 & Vacuolar iron transporter 1.2 & -3.6 & $\begin{array}{l}\text { cell [GO:0005623]; integral component of membrane } \\
\text { [GO:0016021]; vacuolar membrane [GO:0005774] }\end{array}$ \\
\hline KIL88199.1 & Ferric/cupric reductase transmembrane component 2 & -2.7 & $\begin{array}{l}\text { cell [GO:0005623]; fungal-type vacuole [GO:0000324]; } \\
\text { integral component of membrane [GO:0016021]; plasma } \\
\text { membrane [GO:0005886] }\end{array}$ \\
\hline \multirow[t]{2}{*}{ KIL87695.1 } & Probable deferrochelatase/peroxidase YfeX & -2.5 & cytoplasm [GO:0005737]; cytosol [GO:0005829] \\
\hline & Virulence & & \\
\hline KIL88590.1 & Polyketide synthase PksJ & -5.1 & cytoplasm [GO:0005737] \\
\hline KIL84575.1 & Peroxisomal catalase & -4.8 & $\begin{array}{l}\text { fungal-type cell wall [GO:0009277]; peroxisome } \\
\text { [GO:0005777] }\end{array}$ \\
\hline KIL95888.1 & Manganese peroxidase 2 & -4.2 & extracellular region [GO:0005576] \\
\hline KIL89374.1 & Probable polyketide synthase 1 & -3.9 & $\mathrm{NF}$ \\
\hline KIL93997.1 & Protein SnodProt1 & -3.3 & extracellular region [GO:0005576] \\
\hline KIL85985.1 & Alcohol dehydrogenase 1 & -3.2 & cytoplasm [GO:0005737] \\
\hline KIL89373.1 & Transcription factor MYB98 & -2.9 & nucleus [GO:0005634] \\
\hline KIL89340.1 & Fumitremorgin C synthase & -2.5 & $\begin{array}{l}\text { cytoplasm [GO:0005737]; integral component of } \\
\text { membrane [GO:0016021]; intracellular membrane-bounded } \\
\text { organelle [GO:0043231] }\end{array}$ \\
\hline KIL93322.1 & Laccase-2 & -2.2 & extracellular region [GO:0005576] \\
\hline KIL93994.1 & Oxalate decarboxylase OxdC (Organic Acid) & -2.2 & cytoplasm [GO:0005737] \\
\hline KIL95972.1 & $\begin{array}{l}\text { Acyl-coenzyme A:6-aminopenicillanic-acid-acyltransferase } \\
40 \mathrm{kDa} \text { form }\end{array}$ & -2.2 & $\mathrm{NF}$ \\
\hline KIL90502.1 & Aldehyde dehydrogenase & -2.1 & cytoplasm [GO:0005737] \\
\hline \multirow[t]{2}{*}{ KIL87641.1 } & 6-hydroxynicotinate 3-monooxygenase & -2.1 & NF \\
\hline & Detoxification/Stress & & \\
\hline KIL86447.1 & Cytochrome P450 52A11 & -4.1 & membrane [GO:0016020] \\
\hline KIL88204.1 & Phenol 2-monooxygenase & -3.9 & $\mathrm{NF}$ \\
\hline KIL89371.1 & Ent-kaurene oxidase & -3.8 & integral component of membrane [GO:0016021] \\
\hline KIL88419.1 & Glutathione reductase & -2.7 & $\begin{array}{l}\text { cell [GO:0005623]; cytosol [GO:0005829]; mitochondrion } \\
\text { [GO:0005739]; nucleus [GO:0005634] }\end{array}$ \\
\hline KIL87166.1 & Disulfide-bond oxidoreductase YfcG & -2.5 & $\mathrm{NF}$ \\
\hline KIL87179.1 & Putative dioxygenase subunit alpha YeaW & -2.1 & $\mathrm{NF}$ \\
\hline KIL95756.1 & Apoptosis-inducing factor 1 & -2 & $\begin{array}{l}\text { cytosol [GO:0005829]; mitochondrial inner membrane } \\
\text { [GO:0005743]; mitochondrial outer membrane } \\
\text { [GO:0005741]; nucleus [GO:0005634] }\end{array}$ \\
\hline KIL89827.1 & $\begin{array}{l}\text { Putative glutathione-dependent formaldehyde-activating } \\
\text { enzyme }\end{array}$ & -2 & NF \\
\hline
\end{tabular}

Differentially expressed genes were filtered to those with $\log _{2}($ Fold Change) $\leq-2$. Subcellular localization is given based on gene ontology. NF = not found.

processes, including ion binding, transport, membranerelated functions, oxidoreductase activity, and lipid metabolic processes (Table 12).

\section{KEGG Pathway Analysis During Caryopsis Colonization}

Caryopsis colonization (in the absence of $\mathrm{Al}$ ) was associated with an increase in 23 DEGs associated with carbon metabolism, and an increase in 10 DEGs associated with the tricarboxylic acid cycle (TCA cycle). Additionally, a decrease in 5 DEGs associated with N-Glycan biosynthesis was observed in fungal tissues samples colonizing A. fatua caryopses.

\section{DISCUSSION}

Caryopsis colonization resulted in induction of F.a.1 genes associated with virulence, stress/defense, detoxification, organic acid metabolism, basic metabolism, transport, and amino acid/peptide/protein metabolism. At the same time, repression of genes associated with iron metabolism, stress/defense, organic acid metabolism, metal-related metabolism, and basic metabolism was observed. These results suggest a shift in gene expression related to fundamental biological functions occurs during caryopsis colonization. It should be noted that future researchers might consider sampling fungal tissues in a spatial manner that includes sampling the zone of fungal 
TABLE 10 | Enriched and depleted gene ontology terms associated with Al exposure in the absence of the caryopses (FOA).

\begin{tabular}{|c|c|c|}
\hline \multicolumn{3}{|c|}{ Enriched } \\
\hline Term Type & Description & DEG \\
\hline Biological process & Biological process & 860 \\
\hline Biological process & Metabolic process & 686 \\
\hline Molecular function & Catalytic activity & 658 \\
\hline Biological process & Single-organism process & 530 \\
\hline Biological process & Single-organism metabolic process & 362 \\
\hline Molecular function & Oxidoreductase activity & 221 \\
\hline Biological process & Oxidation-reduction process & 218 \\
\hline Biological process & Organonitrogen compound metabolic process & 152 \\
\hline Biological process & Small molecule metabolic process & 128 \\
\hline Biological process & Single-organism biosynthetic process & 121 \\
\hline Biological process & Organonitrogen compound biosynthetic process & 102 \\
\hline Biological process & Carboxylic acid metabolic process & 86 \\
\hline Biological process & Oxoacid metabolic process & 86 \\
\hline Biological process & Organic acid metabolic process & 86 \\
\hline Biological process & Cellular amino acid metabolic process & 58 \\
\hline Molecular function & Lyase activity & 56 \\
\hline Molecular function & Transferase activity, transferring acyl groups & 51 \\
\hline Biological process & Small molecule biosynthetic process & 47 \\
\hline Biological process & Alpha-amino acid metabolic process & 37 \\
\hline Biological process & Organic acid biosynthetic process & 35 \\
\hline Biological process & Carboxylic acid biosynthetic process & 35 \\
\hline Molecular function & Active transmembrane transporter activity & 26 \\
\hline Molecular function & Hydrolase activity, acting on acid anhydrides, catalyzing transmembrane movement of substances & 25 \\
\hline Molecular function & Primary active transmembrane transporter activity & 23 \\
\hline Molecular function & P-P-bond-hydrolysis-driven transmembrane transporter activity & 23 \\
\hline Molecular function & Pyridoxal phosphate binding & 23 \\
\hline Molecular function & ATPase activity, coupled to transmembrane movement of substances & 22 \\
\hline Molecular function & ATPase activity, coupled to movement of substances & 22 \\
\hline Molecular function & ATPase activity, coupled & 22 \\
\hline Molecular function & Carbon-carbon lyase activity & 21 \\
\hline Molecular function & Carboxy-lyase activity & 14 \\
\hline Biological process & Glutamine family amino acid metabolic process & 12 \\
\hline Biological process & Energy coupled proton transport, down electrochemical gradient & 9 \\
\hline Biological process & ATP synthesis coupled proton transport & 9 \\
\hline Molecular function & Carboxylic acid binding & 7 \\
\hline Molecular function & Organic acid binding & 7 \\
\hline Molecular function & Transferase activity, transferring acyl groups, acyl groups converted into alkyl on transfer & 6 \\
\hline Mmolecular function & Amino acid binding & 6 \\
\hline Biological process & Pyridine-containing compound biosynthetic process & 6 \\
\hline Molecular function & Proton-transporting ATP synthase activity, rotational mechanism & 5 \\
\hline Molecular function & ATPase activity, coupled to transmembrane movement of ions, rotational mechanism & 5 \\
\hline Molecular function & Cation-transporting ATPase activity & 5 \\
\hline Molecular function & ATPase activity, coupled to transmembrane movement of ions & 5 \\
\hline Biological process & Organic hydroxy compound biosynthetic process & 5 \\
\hline
\end{tabular}

Depleted

Term Type

Biological process

Molecular function

Biological process

Biological process

Molecular function

\section{Description}

DEG

Bbiological regulation

\section{G}

\section{0} 58 30 62 21 18 52 21 02 6 6 6 1 7 37 5 5 3 3 23 22 2 2

.


TABLE 10 | Continued

Depleted

\begin{tabular}{|c|c|c|}
\hline Term Type & Description & DEG \\
\hline Molecular function & Transition metal ion binding & 161 \\
\hline Molecular function & Zinc ion binding & 122 \\
\hline Molecular function & Nucleic acid binding transcription factor activity & 87 \\
\hline Molecular function & Transcription factor activity, sequence-specific DNA binding & 87 \\
\hline Molecular function & RNA polymerase II transcription factor activity, sequence-specific DNA binding & 60 \\
\hline Molecular function & Heme binding & 39 \\
\hline Mmolecular function & Tetrapyrrole binding & 39 \\
\hline Molecular function & Iron ion binding & 36 \\
\hline Molecular function & Oxidoreductase activity, acting on single donors with incorporation of molecular oxygen & 13 \\
\hline Biological process & Siroheme biosynthetic process & 12 \\
\hline Molecular function & Precorrin-2 dehydrogenase activity & 12 \\
\hline Biological process & Siroheme metabolic process & 12 \\
\hline Molecular function & Ooxidoreductase activity, acting on peroxide as acceptor & 10 \\
\hline Molecular function & Peroxidase activity & 8 \\
\hline
\end{tabular}

DEG is the number of differentially expressed genes induced by Al in the absence of the caryopsis. The darker the DEG cell, the higher the number of DEGs.

material directly in contact with the caryopsis separately from the remaining hyphal mat. A more spatially refined sampling method might also reveal more information with respect to GO enrichment and KEGG pathway analyses at specific interaction sites.

Nevertheless, the presented results reveal many biological mechanisms associated with caryopsis colonization. Notably, AKR7L: Aflatoxin B1 aldehyde reductase member 4 was strongly induced, suggesting a role for aflatoxin degradation during F. avenaceum caryopsis colonization. Previous work suggests Fusarium and Aspergillus species (which produce aflatoxins) can be the primary fungi associated with post-harvest mycotoxin contaminated wheat and corn (Ali et al., 1998; Del Palacio et al., 2016). Several oxidoreductase genes were induced during caryopsis colonization (Table $\mathbf{1}$ ), which is of relevance because the $F$. avenaceum genome has been shown to be enriched in oxidoreductase genes, several of which were induced during colonization of barley plants (Lysøe et al., 2014). Additionally, in the current study, many genes related to oxidative stress were induced during caryopsis colonization, including peroxisomal

TABLE 11 | KEGG pathway terms associated with Al exposure in the absence of the caryopses (FOA).

\begin{tabular}{lc}
\hline Term & DEG \\
\hline Biosynthesis of secondary metabolites & 108 \\
Biosynthesis of amino acids & 64 \\
Carbon metabolism & 44 \\
2-Oxocarboxylic acid metabolism & 24 \\
Cysteine and methionine metabolism & 20 \\
Valine, leucine and isoleucine degradation & 18 \\
Propanoate metabolism & 13 \\
Lysine biosynthesis & 11 \\
\hline DEG is the number of differentially expressed genes induced by Al in the absence \\
of the caryopsis. The darker the DEG cell, the higher the number of DEGs.
\end{tabular}

of the caryopsis. The darker the DEG cell, the higher the number of DEGs. catalase and catalase-1 (cat-1). Others have found Fusarium isolates with a greater capacity to cope with oxidative stress also exhibit stronger virulence (Ponts et al., 2009). Together these results suggest oxidoreductase genes are key to $F$. avenaceum pathogenicity of both seeds and developed plant tissues, likely through mitigating oxidative stress. Further overlap was observed between the results of the current study and those of Lysøe et al., 2014, including induction of the same or related genes, such as, NADH-related genes, an ATP synthase subunit, an extracellular serine-rich protein, heat shock proteins, an iron-sulfur cluster assembly protein, cytochrome p450, and others (Table 1 and Supplementary Table S1). Heat shock protein 90 is required for virulence and development in F. graminearum (Bui et al., 2016), and while this heat shock protein was not induced during caryopsis colonization in the current study, several others were, with the highest expression observed in HSP31 (Table 1); this suggests a role for other heat shock proteins in the virulence of Fusarium species. Other virulence-related genes induced in the current study included ga4 desaturase and ent-kaurene oxidase; both are involved in the production of gibberellic acid, which is also thought to play a role in fungal pathogenesis (Malonek et al., 2005; Chanclud and Morel, 2016).

Many differentially induced genes were unique to the present study as compared with Lysøe et al. (2014), including those involved in the metabolism of the organic acids, oxalate and malate. Additionally, nitrogen metabolism genes were induced during caryopsis colonization, including urea amidolyase and nitrite reductase. Many genes related to carbon metabolism were induced during caryopsis colonization, including STL1 (a sugar transporter), ght1 (a glucose transporter), glcA (glucan endo-1,3-beta-glucosidase A1), grg-1 (glucose-repressible gene protein), and Gpd2 (glycerol-3-phosphate dehydrogenase). In studies with F. graminearum, STL1 has been shown to be involved in interactions with living verses dead wheat tissues, and is thought to be induced by plant signals (Boedi et al., 2016). While the precise role of grg-1 remains unknown in Fusarium 
TABLE 12 | Enriched gene ontology terms associated with Al exposure in the presence of caryopses (FA vs. FOA).

\begin{tabular}{|c|c|c|}
\hline Term Type & Description & DEG \\
\hline Biological process & Single-organism process & 174 \\
\hline Biological process & Single-organism cellular process & 110 \\
\hline Cellular component & Membrane & 107 \\
\hline Molecular function & Ion binding & 82 \\
\hline Biological process & Localization & 71 \\
\hline Biological process & Transport & 69 \\
\hline Biological process & Establishment of localization & 69 \\
\hline Cellular component & Membrane part & 69 \\
\hline Cellular component & Integral component of membrane & 63 \\
\hline Cellular component & Intrinsic component of membrane & 63 \\
\hline Biological process & Single-organism localization & 59 \\
\hline Biological process & Single-organism transport & 58 \\
\hline Molecular function & Anion binding & 48 \\
\hline Biological process & Transmembrane transport & 40 \\
\hline Molecular function & Transporter activity & 40 \\
\hline Molecular function & Transmembrane transporter activity & 37 \\
\hline Biological process & Lipid metabolic process & 32 \\
\hline Molecular function & Oxidoreductase activity, acting on paired donors, with incorporation or reduction of molecular oxygen & 15 \\
\hline Molecular function & Flavin adenine dinucleotide binding & 15 \\
\hline Molecular function & Monooxygenase activity & 7 \\
\hline Molecular function & Protein tyrosine phosphatase activity & 5 \\
\hline Molecular function & Phosphoprotein phosphatase activity & 5 \\
\hline Biological process & Protein dephosphorylation & 5 \\
\hline Biological process & Amino acid transmembrane transport & 4 \\
\hline Biological process & Anion transmembrane transport & 4 \\
\hline Biological process & Organic acid transmembrane transport & 4 \\
\hline Molecular function & Protein tyrosine/serine/threonine phosphatase activity & 4 \\
\hline Molecular function & N,N-dimethylaniline monooxygenase activity & 4 \\
\hline Cellular component & Photosystem II reaction center & 4 \\
\hline Molecular function & O-acyltransferase activity & 4 \\
\hline Molecular function & Primary amine oxidase activity & 2 \\
\hline Molecular function & Calcium-dependent phospholipid binding & 2 \\
\hline Molecular function & Sodium:proton antiporter activity & 1 \\
\hline Molecular function & Glycogen (starch) synthase activity & 1 \\
\hline Biological process & Glycogen metabolic process & 1 \\
\hline Biological process & Glycogen biosynthetic process & 1 \\
\hline Biological process & Energy reserve metabolic process & 1 \\
\hline Biological process & Cobalamin transport & 1 \\
\hline Biological process & Vitamin transport & 1 \\
\hline Molecular function & Calcium activated cation channel activity & 1 \\
\hline Molecular function & Calcium-activated potassium channel activity & 1 \\
\hline Molecular function & Ion gated channel activity & 1 \\
\hline Cellular component & Acetyl-CoA carboxylase complex & 1 \\
\hline Molecular function & Acetyl-CoA carboxylase activity & 1 \\
\hline Molecular function & CoA carboxylase activity & 1 \\
\hline Molecular function & Ligase activity, forming carbon-carbon bonds & 1 \\
\hline
\end{tabular}

DEG is the number of differentially expressed genes induced by Al in the absence of the caryopsis. The darker the DEG cell, the higher the number of DEGs.

species, it is known that glucose repression is intimately linked with fungal-driven cell wall degradation and is necessary for virulence (Tonukari et al., 2000; Ospina-Giraldo et al., 2003). The results suggest a role of $g r g-1$ in A. fatua caryopsis colonization. The gpd2 gene has been shown to be necessary for glycerol utilization, and deletion of the gene results in reduced virulence of Pyricularia oryzae (Shi et al., 2018). Several phosphatase genes were induced during caryopsis colonization, which is of relevance because not only is phosphate turnover central to basic biological functions, but phosphatases have also been shown to be crucial to 
virulence in F. graminearum (Yun et al., 2015). Another stressrelated gene that was induced during caryopsis colonization was sed1, which is thought to be involved in cell wall stability (Hagen et al., 2004).

Bioavailable $\mathrm{Al}$ is thought to play a major role in inhibition of many plant pathogenic fungi, including inhibition of virulence and macroconidial germination of Fusarium solani f. sp. phaseoli (Firestone et al., 1983; Kobayashi and Ko, 1985; Meyer et al., 1994; Furuya et al., 1999; Fichtner et al., 2006). Chronic exposure of F.a.1 to sublethal concentrations of $\mathrm{Al}$ in the current study resulted in global transcriptomic changes (Figures 3E,F). Notably, $\mathrm{Al}$ exposure led to induction of siderophore-, iron-, and organic acid-related genes. Fungalderived siderophores and organic acids are known to interact with metals (Renshaw et al., 2002; Sullivan et al., 2012). Aluminum exposure-induced alterations in iron metabolism included induction and repression of genes associated with iron transport, suggesting a general disruption in iron metabolism in response to $\mathrm{Al}$ exposure. Several genes involved in siderophore biosynthesis were induced during $\mathrm{Al}$ exposure, including sidA (L-ornithine $\mathrm{N}(5)$-monooxygenase), which is crucial for viability of Aspergillus nidulans (Eisendle et al., 2003), and is required for full virulence of $F$. graminearum (Greenshields et al., 2007). The siderophore biosynthesis genes, sidD (NRPS4) and sidC (NRPS2) were also induced in response to $\mathrm{Al}$, and are known to be responsible for synthesis of fusarinine $\mathrm{C}$ and ferricrocin, respectively, in Aspergillus fumigatus (Schrettl et al., 2007). In both Cochliobolus heterostrophus and F. graminearum (Gibberella zeae), sidC has been found essential for sexual development, with the phenotype being partially restored in knockout mutants supplemented with iron (Oide et al., 2007). Reduced colony forming unit counts were observed in $\triangle$ sidA and $\Delta$ sidD mutants of $A$. fumigatus used to test the role of fungal siderophores in infecting mice corneas (Leal et al., 2013). Additionally, the transporter, mirB was induced in response to $\mathrm{Al}$ exposure. It has been shown that mirB is involved exclusively in transporting triacetylfusarinine $\mathrm{C}$ (Haas et al., 2003), which has been implicated as playing key roles in iron uptake and virulence of $F$. graminearum (Oide et al., 2015). Another siderophore transporter, mirA, was also induced by $\mathrm{Al}$ toxicity, which has been shown to exclusively transport enterobactin, a bacterial siderophore (Haas et al., 2003). The siderophore transporter sit1, was also induced by $\mathrm{Al}$ exposure. Greenshields et al. (2007), found sit1 was induced by low iron, but was not expressed in infected wheat, suggesting a role in iron metabolism, but not necessarily for virulence. Another siderophore transporter that was induced during $\mathrm{Al}$ toxicity was str3, which is known to be negatively regulated by iron (Pelletier et al., 2003), and is thought to be crucial for low-affinity heme acquisition by Schizosaccharomyces pombe (Normant et al., 2018). A transcript having $93.4 \%$ sequence similarity to bes $A$, ferri-bacillibactin esterase, was also induced in response to $\mathrm{Al}$ exposure. The bes $A$ sequence has also been identified in F. oxysporum (Guo et al., 2014), while, in Bacillus species, the besA protein is involved in liberating iron from Fe-bacillibactin complexes (Abergel et al., 2009). In the context of the findings presented here, an analogous function for the protein may occur in fungal species, as well.

Organic acids are known to play important roles in metal availability through complexation with metal ions, which renders the metal less bioavailable (Jones, 1998), and the phenomenon has been observed in fungi. For instance, oxalic acid production is responsible for zinc and copper tolerance in Aspergillus niger and Penicillium citrinum, and A. niger isolated from lead contaminated soils has been found to secrete large amounts of organic acids (Sullivan et al., 2012; Sazanova et al., 2015). Additionally, malate exudation by Penicillum oxalicum was suggested to be involved in phosphate liberation from $\mathrm{AlPO}_{4}$, $\mathrm{FePO}_{4}$, and $\mathrm{Ca}_{3}\left(\mathrm{PO}_{4}\right)_{2}$ (Gadagi et al., 2007). These findings, along with the fact that malate is thought to be responsible for $\mathrm{Al}$ tolerance in plants (Delhaize and Ryan, 1995; Ryan et al., 1995; Klugh-Stewart and Cumming, 2009), suggests the induction of malate transporters observed in F.a.1 exposed to $\mathrm{Al}$ is likely related to modulating Al bioavailability.

Gene ontology and KEGG pathway analyses also showed $\mathrm{Al}$ exposure was associated with alterations in basic biological processes, including induction of genes related to oxidoreductase activity, oxidation-reduction process, organic acid metabolism, biosynthesis of secondary metabolites, biosynthesis of amino acids, carbon metabolism, 2-oxocarboxylic acid metabolism, and cysteine and methionine metabolism. Alterations in these disparate biological processes suggests $\mathrm{Al}$ toxicity results in changes to the basic metabolism of the fungus. Gene ontology analyses also suggest that uniquely expressed DEGs might also be involved in unique biological processes (Supplementary Table S7), however, these data were filtered to remove GO terms with less than 5 DEGs to identify potentially unique biological functions associated with the uniquely expressed genes. The unfiltered results showing the number of unique DEGs associated with GO terms can be found in Supplementary Table S8.

These results have significance regarding the currently expanding global issue of soil acidification, and associated Al toxicity. It is unclear how soil fungi, particularly pathogens, cope with acid soils and the metals that become toxic at lower $\mathrm{pH}$ levels in acidified soils, at the molecular level. The results presented here suggest siderophores and organic acids are likely involved in $\mathrm{Al}$ toxicity responses in F.a.1. Which, in turn, brings attention to the fact that these interactions in soils and their impacts on weed seed decay have been overlooked to date. The transcriptomic responses of F.a.1 to $\mathrm{Al}$ suggest that $\mathrm{Al}$ toxicity results in dramatic changes in iron metabolism, siderophore metabolism, and organic acid metabolism, simultaneously. This is a key finding because iron homeostasis has been shown to be essential for full virulence of the related pathogenic fungus, $F$. oxysporum (López-Berges et al., 2012). Additionally, siderophore production is known to be important in plant-pathogen interactions, including the pathogenic activity and sexual development of F. graminearum (Greenshields et al., 2007; Oide et al., 2015). A future direction might include examining the influence of $\mathrm{Al}$ (and other metals) on competitiveness and virulence of F.a1 in soils. 
The transcriptome of F.a.1 provided insights regarding the interactions between an oat fungal pathogen, its susceptible host, and aluminum challenge. A complex hierarchy of gene expression produced by aluminum challenge, superseded that of the host interaction. Understanding genes involved in $\mathrm{Al}$ tolerance may be utilized to promote fungal activity under high $\mathrm{Al}$ soil conditions. Additionally, better understanding of fungus-Al interactions could also assist identification and development of plant growth-promoting fungi that can tolerate increased Al bioavailability. Key genes associated with pathogen growth and life cycle, including the formation of spores, conidia, and infection structures were revealed (Table 6 and Supplementary Tables S2, S3). These genes are promising candidates for host-induced gene silencing (HIGS), an RNAibased approach for pathogen suppression that has been deployed against Fusarium spp. (reviewed in Okubara et al., 2019). Additionally, these genes (and others identified here) may be utilized in identifying other fungal strains that may be even more effective in causing weed seedbank decay. Future work might include applying a multi-omic approach to further elucidate and clarify molecular mechanisms of caryopsis colonization and aluminum toxicity in $F$. avenaceum, including metabolomic and proteomic approaches. Additionally, future work could aim to examine the subcellular localization of the proteins involved in caryopsis colonization and $\mathrm{Al}$ toxicity to reveal how $\mathrm{Al}$ and seed colonization influence the subcellular organization of important metabolites, proteins, and metals.

\section{DATA AVAILABILITY STATEMENT}

The RNA sequence datasets generated for this study can be found through the Sequence Read Archive (SRA; SRA accession: PRJNA595343).

\section{REFERENCES}

Abergel, R. J., Zawadzka, A. M., Hoette, T. M., and Raymond, K. N. (2009). Enzymatic hydrolysis of trilactone siderophores: where chiral recognition occurs in enterobactin and bacillibactin iron transport. J. Am. Chem. Soc. 131, 12682-12692. doi: 10.1021/ja903051q

Ali, N., Sardjono, Yamashita, A., and Yoshizawa, T. (1998). Natural co-occurrence of aflatoxins and Fusarium mycotoxins (fumonisins, deoxynivalenol, nivalenol and zearalenone) in corn from Indonesia. Food Addit. Contam. 15, 377-384. doi: 10.1080/02652039809374655

Anders, S., and Huber, W. (2010). Differential expression analysis for sequence count data. Genome Biol. 11:R106. doi: 10.1186/gb-2010-1110-r106

Anders, S., Pyl, P. T., and Huber, W. (2015). HTSeq-a Python framework to work with high-throughput sequencing data. Bioinformatics 31, 166-169. doi: 10.1093/bioinformatics/btu638

Anderson, J. V., Fuerst, E. P., Tedrow, T., Hulke, B., and Kennedy, A. C. (2010). Activation of polyphenol oxidase in dormant wild oat caryopses by a seeddecay isolate of Fusarium avenaceum. J. Agric. Food Chem. 58, 10597-10605. doi: $10.1021 /$ jf102625a

Beckie, H. J., Francis, A., and Hall, L. M. (2012). The biology of Canadian weeds. 27. Avena fatua L. (updated). Can. J. Plant Sci. 92, 1329-1357. doi: 10.4141/ cjps2012-005

Boedi, S., Berger, H., Sieber, C., Münsterkötter, M., Maloku, I., Warth, B., et al. (2016). Comparison of Fusarium graminearum transcriptomes on living or

\section{AUTHOR CONTRIBUTIONS}

RL conceived and performed the experiments, analyzed the data, and was the primary author of the manuscript. PO assisted with experimental design, data analysis, and writing of the manuscript. EF assisted with experimental design, determined PPO activity, and assisted with editing the manuscript. $\mathrm{RH}$ assisted with experimental design, extracted RNA, and provided text regarding the RNA extraction protocol. DG assisted with experimental design. TS assisted with experimental design and editing the manuscript.

\section{FUNDING}

This project was funded by the USDA National Institute of Food and Agriculture (Agriculture and Food Research Initiative), 2013-02322 (Award Number: 2014- 67013-21575), and CRIS Project No. 2090-22000-017-00D (PO).

\section{ACKNOWLEDGMENTS}

The authors would like to thank Nandan Utgikar for assistance completing the initial stages of the experiment, and Anne T. Pollard for growing and providing seed.

\section{SUPPLEMENTARY MATERIAL}

The Supplementary Material for this article can be found online at: https://www.frontiersin.org/articles/10.3389/fmicb. 2020.00051/full\#supplementary-material

dead wheat differentiates substrate-responsive and defense-responsive genes. Front. Microbiol. 7:1113. doi: 10.3389/fmicb.2016.01113

Bui, D.-C., Lee, Y., Lim, J. Y., Fu, M., Kim, J.-C., Choi, G. J., et al. (2016). Heat shock protein 90 is required for sexual and asexual development, virulence, and heat shock response in Fusarium graminearum. Sci. Rep. 6:28154. doi: $10.1038 /$ srep28154

Chanclud, E., and Morel, J.-B. (2016). Plant hormones: a fungal point of view. Mol. Plant Pathol. 17, 1289-1297. doi: 10.1111/mpp.12393

Coordinators, N. R. (2016). Database resources of the national center for biotechnology information. Nucleic Acids Res. 44, D7-D19. doi: 10.1093/nar/ gkv1290

de Luna, L. Z., Kennedy, A. C., Hansen, J. C., Paulitz, T. C., Gallagher, R. S., and Fuerst, E. P. (2011). Mycobiota on wild oat (Avena fatua L.) seed and their caryopsis decay potential. Plant Health Prog. 12:20. doi: 10.1094/php-20110210-01-rs

Del Palacio, A., Bettucci, L., and Pan, D. (2016). Fusarium and Aspergillus mycotoxins contaminating wheat silage for dairy cattle feeding in Uruguay. Braz. J. Microbiol. 47, 1000-1005. doi: 10.1016/j.bjm.2016.06.004

Delhaize, E., and Ryan, P. R. (1995). Aluminum toxicity and tolerance in plants. Plant Physiol. 107, 315-321.

Eddy, S. R. (2011). Accelerated profile HMM searches. PLoS Comput. Biol. 7:e1002195. doi: 10.1371/journal.pcbi.1002195

Eisendle, M., Oberegger, H., Zadra, I., and Haas, H. (2003). The siderophore system is essential for viability of Aspergillus nidulans: functional analysis of two genes encoding l-ornithine N 5-monooxygenase (sidA) and a non-ribosomal peptide 
synthetase (sidC). Mol. Microbiol. 49, 359-375. doi: 10.1046/j.1365-2958.2003. 03586.x

Fichtner, E., Hesterberg, D., Smyth, T., and Shew, H. (2006). Differential sensitivity of Phytophthora parasitica var. nicotianae and Thielaviopsis basicola to monomeric aluminum species. Phytopathology 96, 212-220. doi: 10.1094/ PHYTO-96-0212

Firestone, M., Killham, K., and McColl, J. (1983). Fungal toxicity of mobilized soil aluminum and manganese. Appl. Environ. Microbiol. 46, 758-761.

Foy, C. D. (1984). "Physiological effects of hydrogen, aluminum, and manganese toxicities in acid soil," in Soil Acidity and Liming, ed. F. Adams, (Madison, WI: American Society of Agronomy, Crop Science Society of America, Soil Science Society of America), 57-97.

Fuerst, E. P., Anderson, J. V., Kennedy, A. C., and Gallagher, R. S. (2011). Induction of polyphenol oxidase activity in dormant wild oat (Avena fatua) seeds and caryopses: a defense response to seed decay fungi. Weed Sci. 59, 137-144.

Fuerst, E. P., James, M. S., Pollard, A. T., and Okubara, P. A. (2018). Defense enzyme responses in dormant wild oat and wheat caryopses challenged with a seed decay pathogen. Front. Plant Sci. 8:2259. doi: 10.3389/fpls.2017.02259

Fuerst, E. P., Okubara, P. A., Anderson, J. V., and Morris, C. F. (2014). Polyphenol oxidase as a biochemical seed defense mechanism. Front. Plant Sci. 5:689. doi: 10.3389/fpls.2014.00689

Furuya, H., Takahashi, T., and Matsumoto, T. (1999). Suppression of Fusarium solani f. sp. phaseoli on bean by aluminum in acid soils. Phytopathology 89, 47-52. doi: 10.1094/PHYTO.1999.89.1.47

Gadagi, R., Shin, W., and Sa, T. (2007). "Malic acid mediated aluminum phosphate solubilization by Penicillium oxalicum CBPS-3F-Tsa isolated from Korean paddy rhizosphere soil," in First International Meeting on Microbial Phosphate Solubilization, eds E. Velázquez, and C. Rodríguez-Barrueco, (Dordrecht: Springer), 285-290.

Glick, B. R. (2010). Using soil bacteria to facilitate phytoremediation. Biotechnol. Adv. 28, 367-374. doi: 10.1016/j.biotechadv.2010.02.001

Greenshields, D. L., Liu, G., Feng, J., Selvaraj, G., and Wei, Y. (2007). The siderophore biosynthetic gene SID1, but not the ferroxidase gene FET3, is required for full Fusarium graminearum virulence. Mol. Plant Pathol. 8, 411-421. doi: 10.1111/j.1364-3703.2007.00401.x

Guo, L., Han, L., Yang, L., Zeng, H., Fan, D., Zhu, Y., et al. (2014). Genome and transcriptome analysis of the fungal pathogen Fusarium oxysporum f. sp. cubense causing banana vascular wilt disease. PLoS One 9:e95543. doi: 10.1371/ journal.pone.0095543

Haas, H., Schoeser, M., Lesuisse, E., Ernst, J. F., Parson, W., Abt, B., et al. (2003). Characterization of the Aspergillus nidulans transporters for the siderophores enterobactin and triacetylfusarinine C. Biochem. J. 371(Pt 2), 505-513. doi: 10.1042/BJ20021685

Hagen, I., Ecker, M., Lagorce, A., Francois, J. M., Sestak, S., Rachel, R., et al. (2004). Sed1p and Srllp are required to compensate for cell wall instability in Saccharomyces cerevisiae mutants defective in multiple GPI-anchored mannoproteins. Mol. Microbiol. 52, 1413-1425. doi: 10.1111/j.1365-2958.2004. 04064.x

Jones, D., Dennis, P., Owen, A., and Van Hees, P. (2003). Organic acid behavior in soils-misconceptions and knowledge gaps. Plant Soil 248, 31-41.

Jones, D. L. (1998). Organic acids in the rhizosphere-a critical review. Plant Soil 205, 25-44.

Kanehisa, M., and Goto, S. (2000). KEGG: Kyoto encyclopedia of genes and genomes. Nucleic Acids Res. 28, 27-30.

Klugh-Stewart, K., and Cumming, J. R. (2009). Organic acid exudation by mycorrhizal Andropogon virginicus L. (broomsedge) roots in response to aluminum. Soil Biol. Biochem. 41, 367-373. doi: 10.1016/j.soilbio.2008.11.013

Kobayashi, N., and Ko, W. H. (1985). Nature of suppression of Rhizoctonia solani in Hawaiian soils. Trans. Br. Mycol. Soc. 84, 691-694. doi: 10.1016/S0007-1536(85) 80125-X

Leal, S. M. Jr., Roy, S., Vareechon, C., Carrion, S. D., Clark, H., Lopez-Berges, M. S., et al. (2013). Targeting iron acquisition blocks infection with the fungal pathogens Aspergillus fumigatus and Fusarium oxysporum. PLoS Pathog. 9:e1003436. doi: 10.1371/journal.ppat.1003436

Lewis, R. W., Barth, V. P., Coffey, T., McFarland, C., Huggins, D. R., and Sullivan, T. S. (2018). Altered bacterial communities in long-term no-till soils associated with stratification of soluble aluminum and soil pH. Soil Syst. 2:7.
López-Berges, M. S., Capilla, J., Turrà, D., Schafferer, L., Matthijs, S., Jöchl, C., et al. (2012). Hapx-mediated iron homeostasis is essential for rhizosphere competence and virulence of the soilborne pathogen Fusarium oxysporum. Plant Cell 24, 3805-3822. doi: 10.1105/tpc.112.098624

Lysøe, E., Harris, L. J., Walkowiak, S., Subramaniam, R., Divon, H. H., Riiser, E. S., et al. (2014). The genome of the generalist plant pathogen Fusarium avenaceum is enriched with genes involved in redox, signaling and secondary metabolism. PLoS One 9:e112703. doi: 10.1371/journal.pone.0112703

Malonek, S., Rojas, M. C., Hedden, P., Hopkins, P., and Tudzynski, B. (2005). Restoration of gibberellin production in Fusarium proliferatum by functional complementation of enzymatic blocks. Appl. Environ. Microbiol. 71, 6014-6025. doi: 10.1128/aem.71.10.6014-6025.2005

Meyer, J., Shew, H., and Harrison, U. (1994). Inhibition of germination and growth of Thielaviopsis basicola by aluminum. Phytopathology 84, 598-602.

Normant, V., Mourer, T., and Labbé, S. (2018). The major facilitator transporter Str3 is required for low-affinity heme acquisition in Schizosaccharomyces pombe. J. Biol. Chem. 293, 6349-6362. doi: 10.1074/jbc.RA118.002132

Oide, S., Berthiller, F., Wiesenberger, G., Adam, G., and Turgeon, B. G. (2015). Individual and combined roles of malonichrome, ferricrocin, and TAFC siderophores in Fusarium graminearum pathogenic and sexual development. Front. Microbiol. 5:759. doi: 10.3389/fmicb.2014.00759

Oide, S., Krasnoff, S. B., Gibson, D. M., and Turgeon, B. G. (2007). Intracellular siderophores are essential for ascomycete sexual development in heterothallic Cochliobolus heterostrophus and homothallic Gibberella zeae. Eukaryot. Cell 6, 1339-1353. doi: 10.1128/ec.00111-07

Okubara, P. A., Peetz, A. B., and Sharpe, R. M. (2019). Cereal root interactions with soilborne pathogens-from trait to gene and back. Agronomy 9:188.

Ospina-Giraldo, M. D., Mullins, E., and Kang, S. (2003). Loss of function of the Fusarium oxysporum SNF1 gene reduces virulence on cabbage and Arabidopsis. Curr. Genet. 44, 49-57. doi: 10.1007/s00294-003-0419-y

Pelletier, B., Beaudoin, J., Philpott, C. C., and Labbé, S. (2003). Fep1 represses expression of the fission yeast Schizosaccharomyces pombe siderophore-iron transport system. Nucleic Acids Res. 31, 4332-4344.

Pimentel, D., McNair, S., Janecka, J., Wightman, J., Simmonds, C., O'Connell, C., et al. (2001). Economic and environmental threats of alien plant, animal, and microbe invasions. Agric. Ecosyst. Environ. 84, 1-20. doi: 10.1016/S01678809(00)00178-X

Pollard, A. T. (2018). Seeds vs fungi: an enzymatic battle in the soil seedbank. Seed Sci. Res. 28, 197-214. doi: 10.1017/S0960258518000181

Ponts, N., Couedelo, L., Pinson-Gadais, L., Verdal-Bonnin, M.-N., Barreau, C., and Richard-Forget, F. (2009). Fusarium response to oxidative stress by $\mathrm{H}_{2} \mathrm{O}_{2}$ is trichothecene chemotype-dependent. FEMS Microbiol. Lett. 293, 255-262. doi: 10.1111/j.1574-6968.2009.01521.x

Renshaw, J. C., Robson, G. D., Trinci, A. P. J., Wiebe, M. G., Livens, F. R., Collison, D., et al. (2002). Fungal siderophores: structures, functions and applications. Mycol. Res. 106, 1123-1142. doi: 10.1017/S0953756202006548

Ryan, P., Delhaize, E., and Randall, P. (1995). Malate efflux from root apices and tolerance to aluminium are highly correlated in wheat. Funct. Plant Biol. 22, 531-536. doi: 10.1071/PP9950531

Sazanova, K., Osmolovskaya, N., Schiparev, S., Yakkonen, K., Kuchaeva, L., and Vlasov, D. (2015). Organic acids induce tolerance to zinc-and copper-exposed fungi under various growth conditions. Curr. Microbiol. 70, 520-527. doi: 10. 1007/s00284-014-0751-0

Schrettl, M., Bignell, E., Kragl, C., Sabiha, Y., Loss, O., Eisendle, M., et al. (2007). Distinct roles for intra- and extracellular siderophores during Aspergillus fumigatus infection. PLoS Pathog. 3:e128. doi: 10.1371/journal.ppat.0030128

Schroder, J. L., Zhang, H., Girma, K., Raun, W. R., Penn, C. J., and Payton, M. E. (2011). Soil acidification from long-term use of nitrogen fertilizers on winter wheat. Soil Sci. Soc. Am. J. 75, 957-964. doi: 10.2136/sssaj2010.0187

Shi, Y., Wang, H., Yan, Y., Cao, H., Liu, X., Lin, F., et al. (2018). Glycerol-3phosphate shuttle is involved in development and virulence in the rice blast fungus Pyricularia oryzae. Front. Plant Sci. 9:687. doi: 10.3389/fpls.2018.00687

Sullivan, T. S., Gottel, N. R., Basta, N., Jardine, P. M., and Schadt, C. W. (2012). Firing range soils yield a diverse array of fungal isolates capable of organic acid production and $\mathrm{Pb}$ mineral solubilization. Appl. Environ. Microbiol. 78, 6078-6086. doi: 10.1128/AEM.01091-12 
Tonukari, N. J., Scott-Craig, J. S., and Waltonb, J. D. (2000). The Cochliobolus carbonum SNF1 gene is required for cell wall-degrading enzyme expression and virulence on maize. Plant Cell 12, 237-247. doi: 10.1105/tpc.12.2.237

Trapnell, C., Pachter, L., and Salzberg, S. L. (2009). TopHat: discovering splice junctions with RNA-Seq. Bioinformatics 25, 1105-1111. doi: 10.1093/ bioinformatics/btp 120

UniProt Consortium (2018). UniProt: a worldwide hub of protein knowledge. Nucleic Acids Res. 47, D506-D515. doi: 10.1093/nar/gky1049

von Uexküll, H. R., and Mutert, E. (1995). Global extent, development and economic impact of acid soils. Plant Soil 171, 1-15. doi: 10.1007/bf0000 9558

Walkowiak, S., Rowland, O., Rodrigue, N., and Subramaniam, R. (2016). Whole genome sequencing and comparative genomics of closely related Fusarium head blight fungi: Fusarium graminearum, F. meridionale and F. asiaticum. BMC Genomics 17:1014. doi: 10.1186/s12864-016-3371-1
Yun, Y., Liu, Z., Yin, Y., Jiang, J., Chen, Y., Xu, J.-R., et al. (2015). Functional analysis of the Fusarium graminearum phosphatome. New Phytol. 207, 119-134. doi: $10.1111 / \mathrm{nph} .13374$

Conflict of Interest: The authors declare that the research was conducted in the absence of any commercial or financial relationships that could be construed as a potential conflict of interest.

Copyright (c) 2020 Lewis, Okubara, Fuerst, He, Gang and Sullivan. This is an openaccess article distributed under the terms of the Creative Commons Attribution License (CC BY). The use, distribution or reproduction in other forums is permitted, provided the original author(s) and the copyright owner(s) are credited and that the original publication in this journal is cited, in accordance with accepted academic practice. No use, distribution or reproduction is permitted which does not comply with these terms. 